\title{
Zeitschrift
}

für

Untersuchung der Nahrungs- und Genußmittel,

sowie der Gebrauchsgegenstïnde.

\section{Beiträge zur Zersetzung der Futter- und Nahrungsmittel durch Kleinwesen.}

\author{
Von
}

J. König und A. Spieckermann in Münster i. W.

\section{VI. Über die Zersetzung von pflanzlichen Futtermitteln bei Luftabschluf.}

\author{
Ausgeführt von H. Kuttenkeuler.
}

In einer früheren von A. Olig ${ }^{1}$ ) ausgeführten Arbeit ist nachgewiesen worden, daß in Baumwollsaatmehl mit etwa $50 \%$ Wasser sich die Zersetzung bei Luftabschluß auf eine teilweise Vergärung der Kohlenhydrate zu organischen Säuren, Wasserstoff und Kohlensäure beschränkte und die Proteine nur in geringem Grade angegriffen wurden. Proteinzersetzende obligate Anaërobier traten in diesem Falle nicht auf und die Reaktion blieb andauernd sauer.

Auch bei Luftzutritt trat anfangs eine saure Gärung ein. Dann entwickelten sich in den oberflächlichen Teilen des Mehles säurezerstörende Pilze und im Anschlusse daran proteinzersetzende Bakterien vom Typus des Bacillus mesentericus vulgatus, die das Protein in hohem Grade bis zu Ammoniak abbauten. Obligate Anaërobier hat Olig auch unter diesen Umständen nicht beobachtet.

Bei späteren Untersuchungen hat sich nun gezeigt, daß in dem bei Luftzutritt faulenden Baumwollsaatmehl, sobald die Reaktion der ganzen Masse alkalisch geworden ist, sich im Innern doeh proteinzersetzende obligate Anaërobier entwickeln.

Da Olig's Beobaehtungen über das Verhalten des Baumwollsaatmehls bei Luftabschluß sich auf einen einzigen Versuch beschränkten, so erschien es wünschenswert, die Vorgänge bei der Zersetzung, dieses und ähnlicher Kraftfuttermittel untèr Luftabschluf noch einmal genauer zu verfolgen.

Betreffs der früheren Literatur über die Vorgänge bei der Fäulnis und die Fäulnisbakterien sei auf die von Olig gegebene Zusammenstellung, sowie auf Lafar's Technische Mykologie Bd. III verwiesen.

Für unsere Untersuchungen sind eine Reihe der bei der Olfabrikation verbleibenden Rückstände benutzt worden, nämlich Baumwollsaat-, Erdnuß-, Sesam-, Lein-' Raps-, Rübsen-, Palmkern-, Palmnufo- und Kokosnußßmehl, ferner das bei der Herstellung

1) Die Zersetzung pflanzlicher Futter- and Nahrungsmittel durch Bakterien. InauguralDissertation Münster 1903; auch diese Zeitschrift 1903, 6, 193. 
der Reisstärke bezw. des Kochreises abfallende Reismehl. Alle diese Futtermittel sind bekanntlich durch einen verhältnismäBig hohen Gehalt an Protein und Fetf gekennzeichnet. Die verschiedenen Mehle wurden mit soviel Wasser durchfeuchtet, daP eine Vermehrung der Bakterien eintrat. Die faulenden Mehle wurden jeweilig auf die in ihnen enthaltenen Bakterien und ihre chemischen Veränderungen untersucht. Die Bedeutung der verschiedenen Bakterienarten für die beobachteten Zersetzungen wurde erforderlichenfalls durch Einwirkung ihrer Reinkulturen auf die sterilisierten Futtermittel zu ermitteln gesucht. Schließlich wurden mit Futtermitteln in verschiedenen Stufen der Zersetzung Fütterungsversuche vorgenommen.

Die Arbeit zerfällt also in einen bakteriologischen und einen chemischen Teil, verbunden mit Fütterungsversuchen:

\section{Bakteriologische Untersuchungen.}

Es sollte festgestellt werden, ob 1. die Zersetzung unter Luftabschluß auch bei anderen Kraftfuttermitteln in der von Olig nur gelegentlich an einer Probe Baumwollsaatmehl beobachteten Weise verläuft,

2. die Fäulnis bei Luftzutritt wirklich nur durch Aërobier bewirkt wird, oder ob hierbei nicht in späteren Stufen auch obligate Anaërobier mitwirken.

Alle im folgenden beschriebenen Versuche sind, soweit nicht anders angegeben ist, bei der für praktische Verhältnisse in Betracht kommenden Temperatur von etwa $15-20^{\circ}$ durchgeführt.

Betreffs der Feuchtigkeit, die für die Entwickelung der Bakterien nötig ist, sind die Versuchsergebnisse W. Bremer's ${ }^{1}$ ) beim Baumwollsaatmehl von uns beim SesammehI nachgeprüft und bestätigt worden, wie die folgende Ubersicht zeigt:

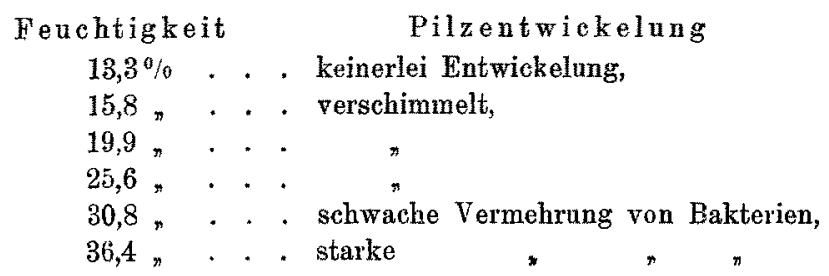

Es liegt also auch bei dem Sesammehl das Feuchtigkeitsminimum für das Schimmeln bei etwa $14 \%$, für die Vermehrung der Bakterien bei etwas über $30 \%$. Durch einige Versuchsreihen mit ErdnuB- und Leinmehl ist ferner vor Einleitung der Hauptversuche festgestellt worden, ob der Feuchtigkeitsgrad auf die Zusammensetzung der Bakterienflora etwa einen ähnlichen Einfluß hat, wie nach unseren früheren Versuchen auf die der Schimmelpilzflora. Beim Erdnußmehl wurden Feuchtigkeitsgrade von $25 \%, 30 \%, 35 \%, 40 \%, 45 \%$ und $50 \%$, beim Leinmehl solche von $30 \%, 35 \%, 40 \%$ und $50 \%$ angewendet. Die ErdnuBmehlproben mit $25 \%$ und $30 \%$ Wasser zeigten auch nach drei Wochen keinerlei Bakterienentwickelung; dagegen war sie bei $35 \%$ schon kräftig, sodaß das Minimum zwischen $30 \%$ und $35 \%$ liegen dürte. Beim Leinmehl war bereits bei $30 \%$ Wasser

¡) Diese Zeitschrift 1901, 4, 721. 
eine schwache Vermehrung der Bakterien sichtbar. Doch muß hierbei berücksichtigt werden, dah sich geringe Wassermengen in dem sehr stark zusammenbackenden Leinmehl schwer gleichmäßig verteilen lassen, sodaß die beobachtote geringe Vermehrung der Bakterien vielleicht auf stärkere Durchfeuchtung einzelner Teile zurückzuführen ist. Was die Flora betrifft, so waren die Arten in allen Proben der Mehle, in denen eine Vermebrung überhaupt eingetreten war, gleich. $O b$ das Verhältnis der Zahl der Individuen der verschiedenen Arten bei den verschiedenen Feuchtigkeitsgraden schwankte, ist zahlenmäßig nicht festgestellt worden. Nach dem mikroskopischen Bilde zu schließen, kamen aber auffälige Schwankungen nicht vor. Dagegen zeigte sich der Einfluß des verschiedenen Feuchtigkeitsgrades deutlich in der absoluten Zahl der Individuen, die mit zunehmender Feuchtigkeit stieg. Beim Erdnußmehl trat insofern ein Unterschied hervor, als in den Proben mit steigenden Wassergehalt die Proteinzersetzer sich schneller entwickelten und darin eine schnellere Fäulnis bewirkten als in den Proben mit geringerem Wassergehalt. So faulte die Probe mit 45\% Wasser merklich schneller als die mit $35 \%$, die mit $50 \%$ wieder schneller als die mit $45 \%$ Wasser.

Auf Grund dieser Vorversuche sind die Hauptversuche alle bei $50 \%$ Feuchtigkeit ausgeführt worden, da sich in diesem Falle am besten eine gleichmäßige Mischung herstellen ließ und auch das bei geringen Feuchtigkeitsgraden durch das Zusammenbacken der Mehlteilchen oft störende Schimmeln erheblich gehemmt wurde. Bei Lein-, Palmnuß- und Kokosnußmehl reichen für diesen Zweck $50 \%$ Wasser noch nicht aus, und es sind daber bei diesen Mehlen Mischungen mit 60-700i0 Wasser angewendet worden.

Zum Anfeuchten der Mehle ist Leitungswasser, teils in natürlichem Zustande teils sterilisiert, verwendet worden. Es hat sich bei Vorversuchen ergeben, daß die Bakterienflora des Leitungswassers (in Münster) auf den Verlauf der chemischen Veränderungen in den Mehlen ohne Einfluß ist, daß dagegen die Zusammensetzung der Flora der faulenden Mehle bei Verwendung sterilisierten und nicht sterilisierten Wassers wechseln kann, was leicht verständlich ist. Entscheidend auf den Verlauf der Zersetzungen durch Bakterien wirkt, wie schon die Untersuchungen Olig's gezeigt haben, unter natürlichen Verhältnissen lediglich die chemische Zusammensetzung der Futtermittel. Vertreter der verschiedenen physiologischen Bakteriengruppen sind in den Futtermitteln stets vorhanden. Mit den von uns verwendeten Fultermehlen konnte man ebenso wie mit den Samen und Früchten, aus denen sie hergestellt werden, durch Anreicherungsverfahren mit geeigneten Nährlösungen nach Belieben saure Gärungen oder Proteinfäulnis der verschiedensten Art erzeugen. Andererseits enthälı aber das Leitungswasser in Münster stets Vertreter der physiologischen Gruppe, die bei der Zersetzung der von uns untersuchten Futtermittel immer zuerst erscheint, nämlich der die Kohlenhydrate zu organischen Säuren und Gasen vergärenden Bakterien. Aus diesem Grunde ist eine Abweichung in Verlaufe der chemischen Vorgänge bei Durchfeuchtung der Futtermittel mit keimfreiem oder mit Leitungswasser ausgeschlossen, während in der floristischen Zusammensetzung der physiologischen Bakteriengruppen bisweilen merkliche Unterschiede hervortraten. Insbesondere die eine starke Gasgärung der Kohlenhydrate hervorrufenden Stäbchen aus der Gruppe des Bacterium coli und Bacterium lactis aërogenes traten bei Verwendung von nicht sterilisiertem Leitungswasser stärker in den Vordergrund als bei Verwendung von 
keimfreiem Wasser. Doch ist hierbei anscheinend auch wieder die chemische Zusammensetzung der Mehle von Bedeutung. Im Liein-, Raps- und Rübsenmehl, die in den von uns untersuchten Proben bei Verwendung von sterilisiertem Wasser sehr selten und dann auch nur Spuren von Gasentwickelung zeigten, trat diese auch bei Verwendung nicht sterilisierten Wassers nicht in höherem Maße ein.

Es ist daher zur Anfeuchtung der Futtermehle bei den Hauptversuchen stets nicht. sterilisiertes Leitungswasser verwendet worden, zumal diese Art der Versuchsanordnung zweifellos den natürlichen Verhältuissen am nächsten kommen wird.

Unter Berücksichtigung der eben geschilderten Ergebnisse der Vorversuche sind die Hauptversuche in folgender Weise angeordnet worden:

1. Von KokosnuB-, PalmnuB- und Leinmehl wurden Proben mit $60^{\circ} \%$ Wasser, von den übrigen Mehlen solchè mit $50 \%$ Wasser sehr fest, möglichst ohne Lufteiinschiluß in Reagensigläser gedrückt und unter Luftabschluß: mit alkalischer Pyrogallussäure, in sauerstofffreier Atmosphäre stehen gelassen. In bestimmten Zwischenräumen wurde der Inhalt je eines Rohres bakteriologiseh untersucht.

2. Reis-, Raps-, Rübsen-, KokosnuB- und PalmnuBmebl mit $50 \%$ Feuchtigkeit wurden in größeren Mengen in einer etwa $5 \mathrm{~cm}$ dicken Schicht bei Luftzutritt faulèn gelassen.

Die bakteriologisehe Untersuchung sowohl der äußeren wie der inneren Teile der Masse wurde in Zwischenräumen ausgeführt.

3. ErdnuB-, Sesam-, Rübsen- und Palmkernmehl wurden mit 50\% Wasser, Lein- nnd KokosnuBmehl mit 70\% Wasser in hohe Bechergläser fest eingestampft und an der Luft stehen gelassen. Die Untersuchung wurde zeitweilig sowohl von der oberen Schicht wie rom Innern ausgeführt.

Außer diesen Versuchsreihen, die lediglich bakteriologischen Zwecken dienten, sind auch die für die chemischen Untersuchungen angesetzten Proben bakteriologisch untersucht worden, wobei aber aus naheliegenden Gründen nur der Endzustand berücksichtigt werden konnte.

Für die bakteriologischen Untersuchungen sind sowobl die Mehle von der im chemischen Teile angeführten Zusammensetzung, als auch Proben anderer Herkunft verwendet worden, so daß die Untersuchungsergebnisse allgemeine Gültigkeit haben dürften,

Die bakteriologische Untersuchung geschah in der Weise, daß aus den zu prüfenden Schichten der zersetzten Mehle mit einem sterilisierten Spatel vorsichtig eine Probe entnommen und in sterilisiertem Leitungswasser verteilt wurde. Von dieser Aufschwemmung wurden gefärbte Präparate angelegt, um einen Oberblick über die Verteilung der Formen zu erhalten und sodann in der bekannten Weise Platten gegossen. Als Nährböden verwendeten wir den üblichen $2^{\circ}$ io-igen Fleischwasserpeptonagar und eine $\cdot 10 \%$-ige Gelatine in Leitungswasser mit $0,5 \%$ Pepton, $0,2 \%$ Glykose, $0,1 \%$ primärem Kaliumphosphat und $0,05 \%$ Magnesiumsulfat, die mit Soda gegen Lackmus genau neutralisiert war.

Von einer genauen Bestimmung der rein gezüchteten Bakterienarten muBte abgesehen werden, da das ins Ungeheuere wachsende Untersuchungsmaterial unmöglich nach dieser. Richtung hin zu bewältigen war. Wir haben uns darauf beschränkt, die verschiedenen Bakterienarten soweit zu untersuchen, daf ihre Einreihung in eine 
physiologische Gruppe möglich war. Wir haben geglaubt, auf eine völlige Differentialdiagnose um so mehr verzichten zu dürfen, als die floristische Zusammensetzung der Gruppen je nach den Verhältnissen wechseln dürfte; schon die oben erwähnten $\mathrm{Er}^{\mathrm{r}}$ fahrungen mit sterilisiertem und natürlichem Leitungswasser deuten hierauf hin. Es sind dạher bei den Untersuchungen der Bakterienarten folgende Punkte berücksichtigt worden: Gestalt, Schwärmfähigkeit, Bildung von Endosporen, Wachstum auf Agarund-Gelatineplatten, im Gelatinestich, im Glykoseagarstich, in Zuckerlösungen im Einhorn'schen Gärkölbchen, in Milch, in Zucker-, Lackmus-Bouillon, in $3 \%$-iger Peptonlösung, in Peptonwasser oder Bouillon mit gekochtem Hühnereiweil in hoher Schicht mit und ohne Zusatz von Zuckern unter LuftabschluB.

\section{A. Bakterienflora bei der Zersetzung unter LuftabschluB.}

Bei sämtlichen Futtermitteln trat in diesem Falle eine äuBerlich bemerkbare tiefere Zersetzung nicht ein. Die Proben behielten ihre natürliche Farbe bis zum Abschluß des acht Monate fortgeführten Versuches. Ihre Reaktion war zu allen Zeiten stark sauer, ihr Geruch sauer, aber nie faulig und nicht unangenehm. In manchen von ihnen fand eine lebbafte Gasgärung statt, in anderen nicht. Sehr stark war die Gasgärung im Baumwollsaatmehl, Rapsmehl, ErdnuRmehl, etwas schwächer in Palmnußmehl, Kokosnußmehl und Reismebl, ganz fehlte sie meist im Leinmehl; nur in seltenen Fällen trat in diesem Futtermittel eine örtlich begrenzte, ganz vereinzelte Gasblase auf. Da diese Beobachtung wiederholt gemacht wurde, so scheint die chemische Zusammensetzung der Mehle in dieser Beziehung von wesentlichem Einfluß zu sein, wenn wir zurzeit auch noch nicht sagen können, worin sie besteht. Abweichend von den anderen Futtermitteln bestand die Flora des Leinmehls stets fast ausschließlich aus Kokken, während Stäbchen nur selten und dann auch nur ganz vereinzelt auftraten. Diese Kokken, die auch in den anderen Futtermitteln stets in geringerer oder größerer Zahl gefunden wurden, vergären Zucker zu Milchsäure in starkem Grade ohne Gasentwickelung. Ob auch noch andere organische Säuren dabei entstehen, ist nicht festgestellt worden. Von diesen Kokken sind aus den verschiedenen Mehlen über zwanzig Stämme näher untersucht worden. Morphologisch unterschieden sich diese nicht. Sie wuchsen auf Platten von Gelatine und Agar in sehr kleinen kreisrunden Kolonien, vorwiegend im Innern des Nährbodens, in Agarstrichkulturen als kaum sichtbarer zarter Belag, im Gelatinestich längs des ganzen Stiches; aber nicht an der Oberfläche. Auf festen Nährböden lagen die Kokken meist in Haufen, in flüssigen bildeten sie kurze Keiten von zwei, selten auch längere von sechs bis acht Zellen. Gelatine verflüssigten sie nicht. Die größte Zahl der isolierten Stämme brachte Milch infolge Vergärung der Laktose zu Milchsäure zum Gerinnen. In Lösungen mit $5 \%$ Glykose, $0,5 \%$ Pepton und Nährsalzen wurde von einer größeren Zahl ebenfalls Säure gebildet, von einer kleineren auch in einer éntsprechenden Lösung mit Laktose und von dreien auch in einer solchen mit Mannit: In zuckerfreien Nährlösungen wuchsen diese Kokken nicht. "Die Stärke des Wachštums, die Scbnelligkeit und der Umfang der Säuregärung war bei dèn einzelnen Stämmen sehr verschieden. $O b$ es sich um verschiedene Arten oder nur ùm Rasseủ handelte, ist nicht weiter untersucht worden. Die vielfachen Abstufungen und Übergänge im Gärvermögen lassen letzteres möglich erscheinen, zumal die große Variabilität der Milchsäurebakterien in dieser Beziehung genügend bekannt ist. 
Abgesehen vom Leinmebl, das, wie erwähnt, fast ausschließlich diese Kokkenvegetation aufwies, wurden in allen anderen Futtermitteln Stäbchenbakterien gefunden, die Kohlenhydrate zu Säuren und Gasen vergoren, in Gestalt, Größe und Schwärmfähigkeit teils dem Bacterium coli, teils dem Bacterium lactis aërogenes ähnelten. Die weitaus gröfte Zahl dieser Bakterien zeigte folgenden Typus: schwärmfähig oder nicht schwärmfähig, peptonisieren Gelatine nicht, bringen Milch durch saure Gärung zum Gerinnen, vergären Glykose, zum Teil auch Laktose, zu Wasserstoff und Kohlensäure, wachsen bei Anwesenheit von Glykose gut anaërob, sonst aërob, erzengen in $3 \%$-igem Peptonwasser meist Indol. Einer zweiten Gruppe fehlte die Fähigkeit, Zucker zu Gasen zu vergären, einer dritten, an Zahl geringeren Gruppe, außer der genannten Fähigkeit auch die, Milch durch Säuregärung zum Gerinnen zu bringen. Sie ließen die Milch auch bei langem Stehen unverändert, oder es trat allmählich eine Gerinnung bei neutraler oder schwachalkalischer Reaktion ein. Eine vierte Gruppe, deren Vertreter seltener beobachtet wurden, vergor zwar Glykose zu Kohlensäure, Wasserstoff und organischen Säuren, peptonisierte aber auch Gelatine. Die von Olig im Baumwollsaatmehl seinerzeit gefundenen und etwas genauer beschriebenen Arten sind auch in anderen Futtermitteln wiederholt beobachtet worden. Fassen wir unsere jetzigen Beobachtungen mit den früheren zusammen, so handelt es sich also um eine Gruppe von Stäbchenbakterien mit der ausgesprochenen Fähigkeit, Zucker zu organischen Säuren - Olig fand Essig- und Bernsteinsäure - unter Umständen auch zu Kohlensäure und Wasserstoff zu vergären, die dagegen Proteinstoffe nur in geringem Grade abzubauen vermögen, wofür auch Olig bereits Beweise geliefert hat.

Sämtliche Proben sind sodann wiederholt auf die Anwesenheit obligater Anaërobier in der Weise untersucht worden, daß ein großer Anteil einer wässerigen Aufschwemmung der Mehle in Agarröhrchen (Agar mit 1\% Glykose) mit hoher Schicht verteilt, zehn Minuten auf $75^{\circ}-80^{\circ}$ erwärmt und dann bei $34^{0}$ im Thermostaten längere Zeit aufbewahrt wurde. In keinem Falle ist eine Entwickelung solcher Bakterien beobachtet worden.

Mit der zunehmenden Säuerung fand in allen Futtermitteln ein Absterben der Bakterien statt. Mauchmal blieben die Platten schon nach sechs Wochen steril, nach zehn Wochen wurde nirgends mehr eine Entwickelung von Kolonien der Säuerungsbakterien beobachtet. Dagegen erschienen auf den Agarplatten so alter Kulturen stets vereinzelte Kolonien von Arten der Gruppe des Bacillus mesentericus. Sporen dieser Bakterien sind in allen Futtermitteln enthalten. Daß sich diese Pilze in den sauren Proben vermebrt haben sollten, ist wenig wahrscheinlich. Sie sind fast alle strenge Aërobier und gegen Säure sehr empfindlich. Allenfalls in den ersten Tagen könnten sie in den ja immerhin durch die Art der Herstellung schwach sauerstoffhaltigen feuchten Mehlen ein kümmerliches Dasein führen. Dagegen spricht auch der Umstand, daß sie zu dieser Zeit weder im mikroskopischen Bilde noch auf den Platten erscheinen. Die einfachste Erklärung für die einzelnen Kolonien aus alten Proben ist wohl die, daß die ursprünglich vorhandenen Sporen nach Aufhören der starken Konkurrenz durch die Säurebildner auf den Platten zu Kolonien sich entwickeln können. 


\section{B. Bakterienflorabei der Zersetzung unter Luftzutritt.}

Beim Reis-, Rübsen-, Raps-, KokosnuB- und PalmnuBmeh1, die unter reichlichem Luftzutritt in dünner Schicht von etwa $5 \mathrm{~cm}$ angesetzt waren, trat in der ersten Woche, wie bei den ganz unter Luftabschluß aufbewahrten Proben, eine saure Gärung auf, die durch Kokken and Stäbchen der eben beschriebenen Typen erzeugt wurde. An der Oberfläche der Proben entwickelte sich aber in allen Fällen eine üppige Vegetation von Schimmelpilzen, zuweilen auch Sproßpilzen. Nach zwei Wochen war die unter dieser Schimmeldecke sitzende Schicht der Mehle überall neutral oder schwach alkalisch, roch etwas faulig, war schmierig und verfärbt und im mikroskopischen Bilde erschienen neben den kurzen zarten Stäbchen der Säurebildner größere und längere Stäbchen. Die Kultur ergab, daß es sich um Vertreter der Gruppe der "Kartoffelbacillen" handelte, die das Protein der Futtermittel zersetzten. Der innere Teil der Meble war noch saner und von natürlicher Farbe. Die alkalische, schmierige Schicht wuchs allmählich immer weiter in die Tiefe. Am schnellsten verlief die Fäulnis beim KokosnuBmeh1, das schon nach zwei Wochen einen völlig alkalischen, faulen, stinkenden Brei bildete. Etwas weniger schnell faulten $R \ddot{u b s e n-}$ und Rapsmehl; sie waren erst nach drei bis vier Wochen völlig alkalisch. Dagegen blieben Reis - und Palm nuBmehl lange Zeit sauer. Letzteres war erst in vier Monaten in allen Teilen schwach alkalisch, das Reismehl war zu dieser Zeit schon etwas stärker gefault. Sowohl der alkalische wie der saure Teil wurde anch bei diesen Proben häufiger auf obligate Anaërobier untersucht und es ergab sich, dab, sobald die Masse völlig alkalisch war, solche Bakterien zur Entwickelung gelangten und bald ganz die Oberhand gewannen.

Es sei hier gleich anschließend kurz erwähnt, daß dic Fäulnis bei geringem Luftzutritt, also beim Aufbewahren der feuchten Mehle in hohen Bechergläsern, in derselben Weise verläuft, wie eben beschrieben wurde, nur mit dem Unterschiede, dalo sie den Verhältnissen entsprechend langsumer in die Tiefe dringt und daß manche Futtermittel noch nach längerem Aufbewahren in dieser Weise in den tieferen Schichten eine saure Reaktion zeigen. Besonders hervorgehoben zu werden verdient, dal auch in diesem Falle das Leinmehl insofern eine Sonderstellung einnimmt, als seine Oberfläche sich erst nach langer Zeit mit Schimmel bedeckt und dementsprechend die Fäulnis sehr langsam verläuft.

Obligate Anä̈robier sind in allen von uns untersuchten, ganz verfaulten Mehlen gefunden worden. Wir haben uns auf die Isolierung von Endosporen bildenden Arten beschränkt, zumal andere bisher mit Sicherheit kaùm nachgewiesen worden sind. Zur Isolierung wurde Agar in hoher Sebicht nach dem Vorgange von Liboriu s benutzt. Durch genügende Verdünnung läßt es sich leicht erzielen, daß in den Röhrchen nur wenige Kolonien vorhanden sind, die sich nach Zertrümmerung des Röhrchens bequem rein abstechen lassen. Zuweilen sind auch die von Streng ${ }^{1}$ ) vorgeschlagenen Doppelschalen benutzt worden, die ebenfalls recht brauchbar sind.

Die rein gezüchteten Anaërobier lassen sich in zwei Gruppen teilen: 1. solche, die Protein zersetzen, 2. solche, die dieses nicht zersetzen. Von diesen beiden Gruppen ist nur die erste in höherem Maße in den Kreis der Untersuchungen gezogen worden.

1) Diese Zeitschrift 1904, 8, 611 . 
Von der zweiten Gruppe sei nur erwähnt, daß, sämtliche Kulturen zarte, schlanke Stäbchen zeigten, in denen eine etwa in der Mitte liegende, ovale Spore gebildet wurde, daß sie die Gelatine zum größten Teil nicht verflüssigten, Milch durch Säuregärung unter starkem Buttersäuregeruch zum Gerinnen brachten, aber nie faulig zersetzten, und in zuckerfreien Peptonlösungen suspendiertes Eieralbumin nicht angriffen. Gas wurde von den meisten von ihnen in zuckerhaltigen Nährböden nicht erzeugt. Das Wachstum im Stich in hochgeschichtetem Agar begann erst tief unter der Oberfläche. Einen Übergang zur zweiten Gruppe bildeten einzelne Stämme, die die Milch ohne stärkere saure Reaktion zum Gerinnen brachten und, wie das Entstehen geringer Mengen von Ammoniak zeigte, anscheinend auch das Protein etwas zersetzten, ohne aber einen tieferen Zerfall mit unangenehmem Geruche $z u$ bewirken. Von der die Proteinstoffe zersetzenden Bakteriengruppe sind aus den verschiedensten Futtermehlen bei verschiedenen Gelegenheiten 13 Bakterienstämme gezüchtet, die bei weiterer Untersuchung als gleichartig und bei Vergleich mit einer Kultur des Bacillus putrificus. aus der Sammlung $\mathbf{K} \mathbf{r}$ ál sich als mit diesem identisch erwiesen. Das schließt natürlich nicht aus, daß auch andere anaërobe Proteinzersetzer in Futtermitteln-zur Entwickelung gelangen. Immerhin scheint doch Bacillus putrificus der häufigste zu sein.

Sämtliche Stämme verflüssigten Gelatine, aber verschieden schnell. Bei manchen klärte sich die verflüssigte Gelatine schnell unter Absetzung eines dicken Bodensatzes, bei anderen blieb sie längere Zeit getrübt. Auf Agarplatten (nach Streng) wuchsen rlie Bakterien in unregelmäbig strahligen, nach allen Seiten verzweigten Kolonien. In hoher Schicht von Glykose-Agar, in Peptonlösungen mit versehiedenen, aber nicht allen Zuckern, riefen sie eine lebhafte Gasgärung unter Säuerung der Flüssigkeit hervor. Nähere Angaben bierüber folgen im nächsten Abschnitt. In verdünnter Bouillon oder Peptonwasser suspendiertes, gekochtes Hühnereiweil und Fibrin wurden unter starker Gasentwickelung und ekelhaftem Geruch völlig zersetzt. Dagegen trat in einer rein unorganischen Nährlösung mit gekochtem Eieralbumin kein Wachstum: ein. In Milch wurde das Kasein gefâllt und dann gelöst, so daß sie eine braune, ammoniakaliseh und ekelhaft rièchende, klare Flüssigkeit bildete.

Die Entwickelung der Bakterien ist sowohl in Bouillon als auch in Agar in hoher Schicht verfolgt worden. Als Ausgangsmaterial diente der zwei bis drei Monate alte, in Röhrchen mit verdünnter Bouillon und gekochtem Eiereiweiß abgesetzte Bodensatz, der zum gröbten Teil aus den Sporangien des Pilzes bestand. Diese bleiben auch nach völliger. Ausbildung der Spore erhalten und umschließen letztere bis zur Kèimung. Sie sind-durohgängig an der einen Seite keulenartig aufgetrieben (Trommelschlägelform) und $4-5 \mu$ lang, im dünneren Teil $0,5-1,2 \mu$ im Kopfteil 1,2-2,5 $\mu$ diek; seltener sind Sporangien ohne die keulenartige Erweiterung. Die in ihnen enthaltenen Sporen sind oval, mit glatter Membran, meist 1,75 $\mu$ lang und 1,25 $\mu$ dick. Mit Anilinfarben, sowie mit Jodjodkaliumlösung färben sich die Mèmbranen der Sporangiẹn und Sporen, während irgendwelche Inhaltsstoffe bei deñ ersteren nicht mehr zu erkennen sind. Die Keimung erfolgt in der Weise, daß die Spore allmählich an Größe zunimmt, gleichzeititg Anilinfarben aufzunehmen beginnt und direkt ein Stäbehen bildet, ohne daß ein Abstreifen der Sporenmembran zu beobachten wäre. Die Membran der. Spo. rangien scheint zu verquellen: jedenfalls findet man sie später nicht mehr. Ob diese Keimstäbchen, die merklich dicker sind als die später gebildeten, sofort schwärmen, ist nicht festgestellt worden. Färbt man sie mit vèrdünnter Methylenblaulösung nach 
A. M e ye $\mathbf{r}^{1}$ ), so färben sie sich vollständig, doch werden ein, zwei, zuweilen auch drei kugelige Gebilde besonders dunkel gefärbt. Diese geben -alle Reaktionen des von A. Meyer genauer beschriebenen Volutins und sind daher wohl als solches anzusprechen. Nach etwa 16 Stunden findet man in Bouillonkulturen, die bei $34^{0}$ gewachsen sind, zwei- bis vierstäbige Verbände mit Stäben von $4-5 \mu$ Länge und $0,5-1 \mu$ Dicke, ferner einzelne Stäbe, Verbände mit zweizelligen Stäben und vielzellige Fäden bis zu $60 \mu$ Länge. Alle Formen sind in lebhaftem Schwärmen und besitzen, wie durch die Geißelfärbung nach Löffler leicht zu zeigen ist, zahlreiche peritrich angeordnete Geißeln. Nach 22 Stunden sieht man vorwiegend 'einzelne Schwärmer, die an einem Ende etwas angeschwollen sind und schon dadurch den Be* ginn der Sporenbildung verraten. Nach 40 Stunden findet man schwärmende Sporangien mit deutlich abgegrenzter Spore, nach 64 Stunden sind die fertigen Sporangien zur Ruhe gelangt. Irgendwelche Inhaltsstoffe, wie Fett, Glykogen, Jogen, Volutin, konnten in den Stäbchen und Sporangien zu keiner Zeit nachgewiesen werden. Die Färbung mit verdünnten Anilinfarben ist meist nicht gleichmäßig in den Stäbchen; wodurch aber die verschiedenartige Färbbarkeit des Zellinhaltes bedingt wurde, war nicht zu ergründen. Dic Sporenbildung läßt sich durch Färbungen bis zu einem gewissen Grade verfolgen. Färbt man Bakterien aus Kulturen, die $36-40$ Stunden bei $\cdot 34^{0}$ gostanden haben, vorsichtig nach Gram, so wird die Zellmembran stark violett, das Innere schwach violett gefärbt. In den Stäbchen, in denen die Sporenbildung beginnt, sieht man dann gegen das etwas verdickte Ende zuweilen einen oder auch mehrere dunkler gefärbte kugel- oder linsenförmige Körper. Entfärbt mån sehr stark, so erscheinen die Zellen bis auf die Membran und diese Massen ungefärbt. In einer größeren Anzahl von Stäbchen dagegen sieht man an einem Ende einen von dem dunkleren Plasma sich deutlich abhebenden, ovalen, heller gefärbten Teil, in dessen Mitte ein oft erheblich dunkler gefärbter Kern liegt, dessen Größe sehr verschieden ist. Eine scharfe Abgrenzung des helleren Teiles gegen das dunklere Plasma durch eine Membran ist zunächst nicht zu sehen. Seltener erhält man auch Bilder, in denen das Plasma heller, der abgegrenzte Teil dunkler gefärbt ist, in dem dann wieder ein oder zwei noch stärker gefärbte Kerne zu. sehen sind. Etwas später zeigt sich eine stark violett gefärbte Membran um die Sporenanlagge, deren Inneres, bis auf den noch immer sehr stark sich färbenden Kern, den Farbstoff jetzt nur noch schwach aufnimmt. Schließlich verschwindet auch der Kern und nur die Sporenmembran ist gefärbt. Die Sporangien bleiben farblos, und nur ihre Membran färbt sich kräftig. Untersucht man Sporangien nach etwa 70 Stunden, so bleiben die Sporen ungefärbt, das Plasma des Stäbchens färbt sich matt, zeigt aber zahlreiche: schwach gefärbte Vakuolen und zuweilen einzelne dunkler gefärbte Stellen kleineren oder größeren Umfanges, die bei stärkerer Entfärbung allein gefärbt bleiben. Besonders um die Spore herum sieht man oft. eine dunklere Färbung im Plasma.

Färbt man nicht zu alte Sporangien nach A. Meyer mit. Formalin und verdünnter Fuchsinlösung, so werden die Sporenanlagen je nach dem Alter nicht mehr, oder nur schwach gefärbt; in letzterem Falle zeigt sich in ihrer Mitte stets ein "stark gefärbter Kern. Das Plasma des Sporangiums erscheint mattrosa. In ihm liegen oft ein bis drei meist der Membran angelagerte, dunkelrot gefärbte Körper, über, deren Natur nichts festzustellen war.

$\left.{ }^{1}\right)$ A. Meyer, Praktikum der botan. Bakterienkunde 1903. 
Betreffs des physiologischen Verhaltens wird in einem der folgenden Abschnitte weiteres mitgeteilt werden.

Die wesentlichen Ergebnisse der bakteriologischen Untersuchungen sind also folgende:

1. In den Futtermitteln sind die zu ihrer Zersetzung befähigten Bakterien stets enthalten.

2. Diese vermehren sich bei einem Feuchtigkeitsgehalt der Futtermittel von etwas über $30 \%$.

3. In sämtlichen Futtermitteln kommen sowohl bei Luftzutritt wie bei Luftabschluf zunächst Kokken- und Stäbchenbakterien zur Entwickelung, die die Kohlenbydrate zu Säuren und Gasen vergären.

4. Bei Luftabschluß bleiben sie die einzige Flora.

5. Bei Luftzutritt dagegen entwiekeln sich an der Oberfläche Eumyceten, die die organischen Säuren zerstören. Darauf vermehren sich die Protein zersetzenden aëroben Vertreter der Kartoffelbacillengruppe, unter deren Einfluß die Reaktion der faulenden Masse allmählich nach innen zu alkalisch wird. Sobald dieses geschehen ist, entwickeln sich die obligaten Anaërobier.

6. Die Anaërobier sind teils Buttersäuregärer ohne Einflub auf die Proteine, teils Proteinzersetzer.

7. Der häufigste anaërobe Proteiızersetzer scheint Bacillus putrificus zu sein.

\section{Chemische Untersuchungen.} geschickt:

Über die angewendeten Untersuchungsverfahren sei folgendes voraus-

Die quantitativen Bestimmungen der Gesamt-Stickstoffsubstanz, des Fettes, der Mineralstoffe, sowie der Säuren wurde nach den üblichen Verfahren ausgeführt. Das ReineiweiB wurde nach Stutzer-Barnstein gefällt, die Pentosane wurden durch Fällen des Furfurols mit Phloroglucin und Berechnung nach den von Tollens ${ }^{1}$ ) aufgestellten Tabellen, die Rohfaser mit Glycerin-Schwefelsäure nach J. König ${ }^{2}$ ) bestimmt. Da die so erhaltenen Werte für Rohfaser besonders bei den gefaulten Mehlen bäufig schlecht übereinstimmten, wurden die abgewogenen $3 \mathrm{~g}$ Mehl zunächst in einer Porzellanschale mit Oxalsäure und Wasser mehrmals zur Trockne verdampft, um so eine feinere Zerkleinerung und damit bessere Einwirkung der Glycerin-Schwefelsäure zu erzielen. Die stickstoffreien Extraktstoffe wurden, wie üblich, aus der Differenz: Trockensubstanz - (Rohprotein + Fett + Pentosane + Rohfaser + Asche) berechnet.

Die qualitative Untersuchung der Zersetzungserzeugnisse von Proteinstoffen wurde nach den von Hoppe-Seyler ${ }^{3}$ ) und E. Salkowski ${ }^{4}$ ) beschriebenen Verfahren ausgeführt.

3) Joarn. f. Landw. 1900, 48, 357.

3) Diese Zeitschrift 1898, 1, 1.

3) Hoppe-Se y ler's Handbuch d.physiologisch-u. pathologisch-chem. Analyse. 7. Aufl. 1903.

*) E. Salkowski, Praktikam d. physiol. u. pathol. Chemie, 2. Aufl. 1900. 


\section{A. Untersuchungen über die Zersetzungen in den Futtermittein.}

Erste Versuchsreihe.

Die Zersetzung der Futtermittel unter völligem Abschluß der Luft.

Von Baumwollsaat-, Erdnub-, Sesam-, Rübsen-, Raps-, Reis-, KokosnuB-, Palmkern-, PalmnuB- und Leinmehl wurden 250-350 g, je nach dem Volumen, mit etwa $50 \%$ Wasser, bei den schwerer zu befeuchtenden mit 60 bis $70 \%$ in Bechergläser fest eingedrückt und in einer durch Pyrogallussäure vom Sauerstoff befreiten Atmosphäre etwa zwei Monate stehen gelassen.

Bei allen Mehlen war während dieser Zeit die Farbe normal geblieben; di Reaktion war mehr oder weniger stark sauer; nur bei Kokosnußmehl in der Oberflächenschicht neutral, innen schwach saner, Palmnub-, Raps- und Rübsenmehl zeigten schwache Gasentwickelung, bei Palmkern- und Kokosnulamehl fehlte diese, während sie bei Baumwollsaat-, Erdnuß-, Reis-, Sezam- und Leinmehl sehr stark hervortrat. Bei Baumwollsaat-, Raps-, Erdnuß- und Rübsenmehl war auch die mit einem zinnoberhaltigen Fettstift gemachte Aufschrift an den Gläsern geschwärzt; es hatte hier also jedenfalls eine Schwefelwasserstoffentwickelung stattgefunden.

Die bakteriologische Untersuchung der Proben stieß insofern auf Schwierigkeiten, als die meisten Bakterien durch die andauernde Wirkung der Gärungssäuren abgestorben waren. Auf den Agarplatten wuchsen aus Raps-, Rübsen-, Sesam-, Erdnußund Leinmehl vorwiegend Kolonien von Kokken, aus den anderen Mehlen nur vereinzelte Kolonien von Kartoffelbacillen. Obligate Anaërobier wurden nicht beobachtet. Es mubte daher die rein mikroskopische Untersuchung herangezogen werden, die im wesentlichen das Bild ergab, das bereits im bakteriologischen Teil dieser Arbeit für die unter Luftabschluß gefaulten Proben gezeichnet ist.

Da die Mengen der zu den Versuchen verwendeten Futtermehle nicht genau festgestellt waren, so wurde für die Bilanzaufstellung die Voraussetzung gemacht, daß die Menge der Asche unverändert geblieben war; die Mengen der organischen Stoffe der zersetzten und der natürlichen Mehle wurden daher auf gleiche Aschenmengen umgerechnet. Wenn diesem Verfahren auch wesentliche Fehler nicht anhaften dürften, so sind doch vielleicht hierauf einige Unregelmäßigkeiten in den folgenden Tabellen zurückzuführen; das Endergebnis dürfte indes durch sie nicht wesentlich berührt werden.

Die Untersuchungsergebnisse sind in den 'Tabellen I (S. 188), II (S. 189) und III (S. 190 u. 191) zusammengestellt.

Aus diesen Tabellen geht hervor, daß eine wesentliche Zersetzung der organischen Stoffe unter den eingehaltenen Versuchsbedingungen nicht stattgefunden hat. Der Verlust an Trockenmasse bleibt meist unter $5 \%$ und erreicht nur einmal $6,5 \%$. Es unterscheidet sich in dieser Beziehung die Fäulnis unter völligem Luftabschluß wesentlich von der unter Luftzutritt, bei der die Trockenmasse unter Umständen um über $30 \%$ abnimmt. Den Hauptanteil an dem Massenverlust tragen die sogenannten stickstofffreien Extraktstoffe, die bei den meisten Mehlen zu einem Viertel bis zur Hälfte verschwunden sind. Auch die Pentosane haben in allerdings sehr wechselndem Maße abgenommen. Dagegen zeigt einen stärkeren Verlust an Fett nur das Rapsmehl. Der Gesamt-Stickstoff hat wesentliche Veränderungen nicht 
erfahren. Dagegen hat ein teilweiser Abbau der Proteinstoffe fast überall stattgefunden, der im Reis: und Sesammehl sogar bis. zu erheblicher Höhe steigt. Im wesentlichen ist dieser Abbau anscheinend bei den höher organisierten Stickstoffverbindungen stehen geblieben. Etwas Ammoniak ist überall entstanden, doch beträgt der Ammoniak-Stickstoff von dem an Reinprotein verloren gegangenen Stickstoff bei den meisten Mehlen 15-20\%, bei Rübsen- und Erdnufmehl etwa 30-35\% und nur bei Raps- und Palmnufmehl etwa $100 \%$.

Der Verlauf dieses Versuches zeigt, daß bei allen verwendeten Futtermitteln, wie bereits nach den bakteriologischen Untersuchungen zu vermuten war, bei freiwilliger Zersetzung unter völligem Luftabschlub eigentliche Fäulnis, d. h. tiefgehende Zersetzung, in erster Linie der Proteinstoffe unter Auftreten einer alkalischen Reaktion und eines faulen Geruches, nicht stattfindet, und daß unter diesen Umständen die. streng anaëroben Proteinzereetzer überhaupt nicht zur Entwickelung gëlangen.

Tabelle I.

Prozentuale Zusammensetzung der zu den Versuchen angewendeten Mehle.

1. Natürliche Substanz.

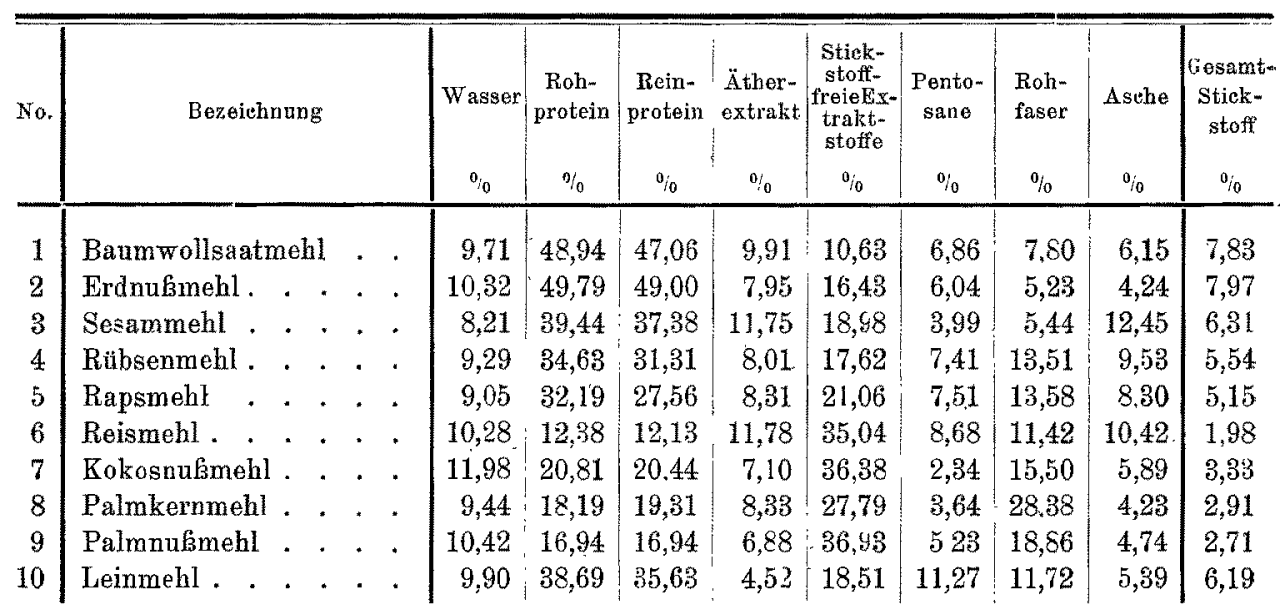

2. Trockensubstanz.

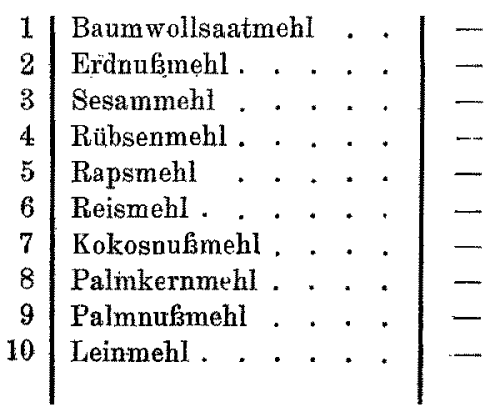

\begin{tabular}{r|r|r|r|r|r|r|r}
54,20 & 52,12 & 10,97 & 11,78 & 7,60 & 8,64 & 6,81 & 8,67 \\
55,52 & 54,64 & 8,86 & 18,38 & 6,73 & 5,83 & 4,73 & 8,89 \\
42,52 & 40,72 & 12,80 & 20,84 & 4,35 & 5,93 & 13,56 & 6,80 \\
38,79 & 34,50 & 8,83 & 18,82 & 8,17 & 14,89 & 10,50 & 6,21 \\
35,39 & 30,30 & 9,14 & 23,14 & 8,27 & 14,93 & 9,13 & 5,66 \\
13,80 & 13,52 & 13,13 & 39,06 & 9,67 & 12,73 & 11,61 & 2,21 \\
23,64 & 23,22 & 8,07 & 41,33 & 2,66 & 17,61 & 6,69 & 3,78 \\
20,09 & 21,32 & 9,20 & 30,68 & 4,02 & 31,34 & 4,67 & 3,21 \\
18,91 & 18,91 & 7,68 & 41,33 & 5,84 & 20,95 & 5,29 & 3,03 \\
42,85 & 39,53 & 5,02 & 20,63 & 12,51 & 13,01 & 5,98 & 6,85 \\
& & & & & & &
\end{tabular}




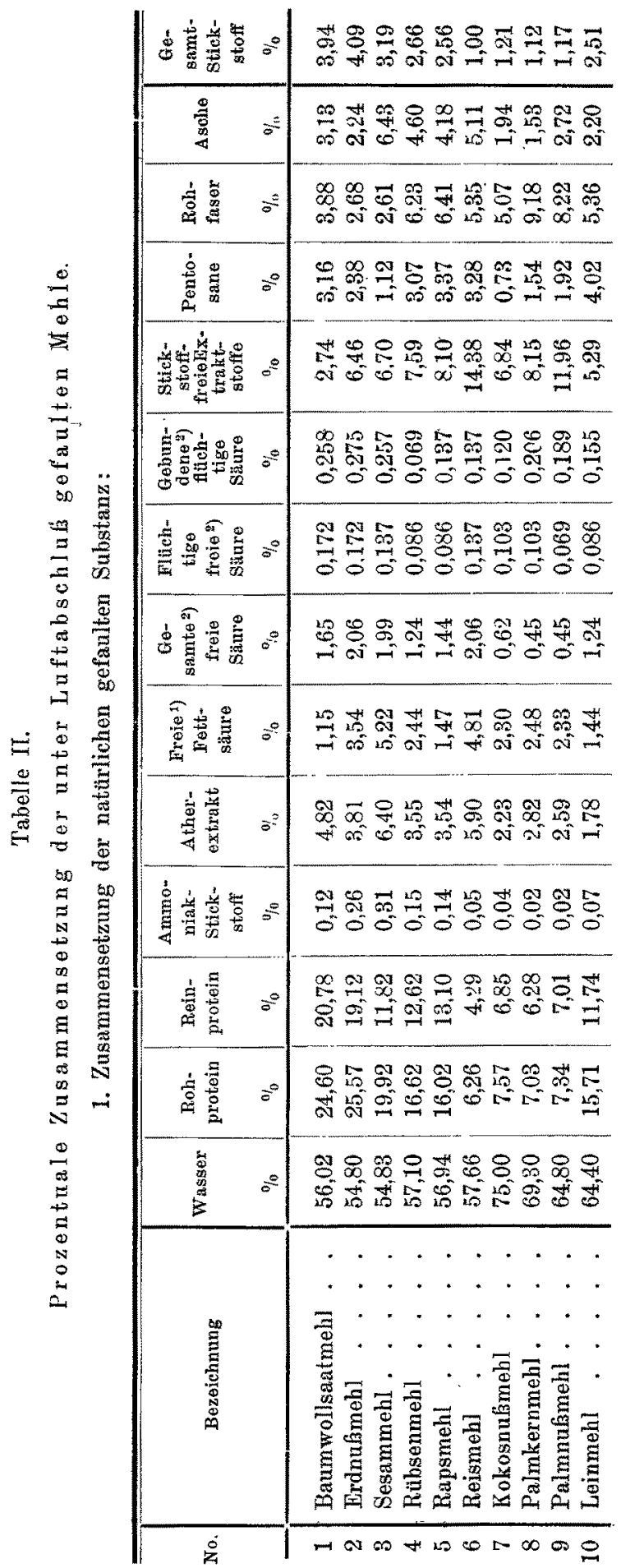

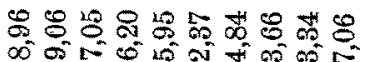

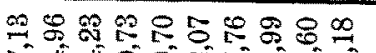

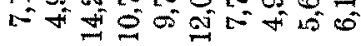

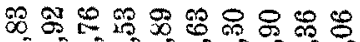

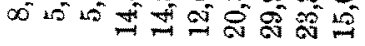

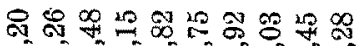

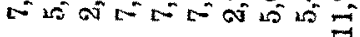

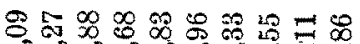

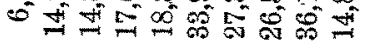

め

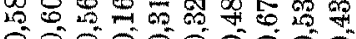
․ㅜㅇ 웅 궁

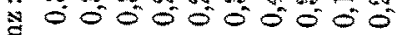
幕

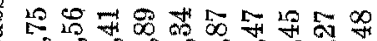

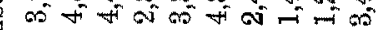

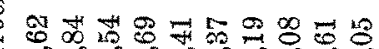
बis $=25$ का

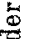

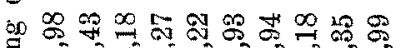

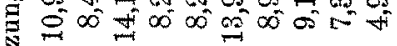
要

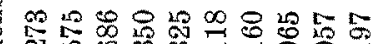
1.

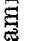

s

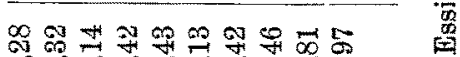
व

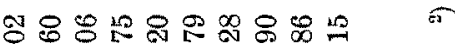

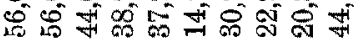

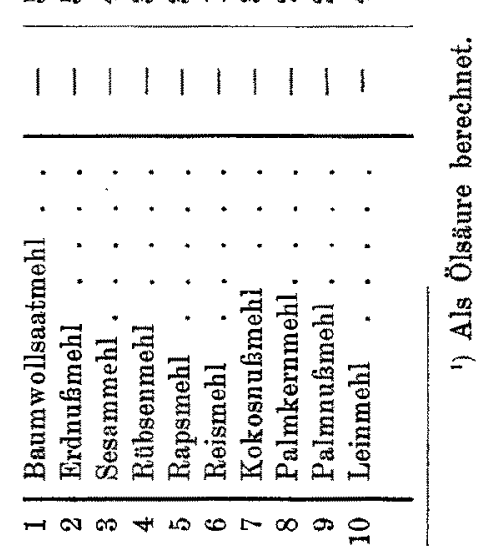




\begin{tabular}{|c|c|c|c|c|c|c|c|c|c|c|c|c|}
\hline 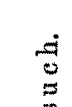 & 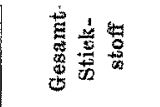 & 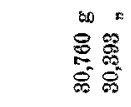 & 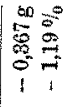 & & 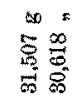 & 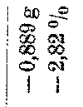 & & 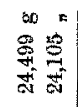 & 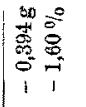 & & 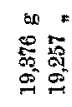 & 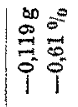 \\
\hline 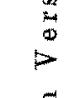 & 㷠 & 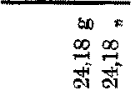 & $\mid \begin{array}{c}0 \\
H+1\end{array}$ & & 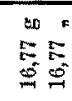 & $+1+1$ & & 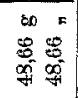 & OO & & 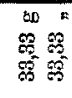 & $\begin{array}{l}00 \\
+1+1\end{array}$ \\
\hline 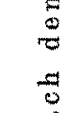 & 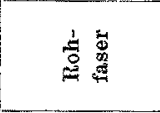 & 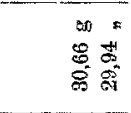 & 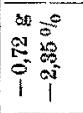 & & 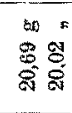 & 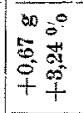 & & 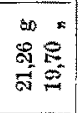 & 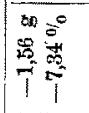 & & 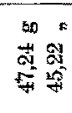 & 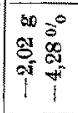 \\
\hline $\begin{array}{l}\stackrel{g}{g} \\
\Xi\end{array}$ & 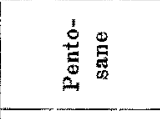 & 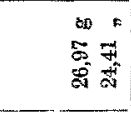 & 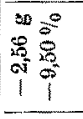 & & 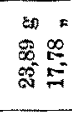 & 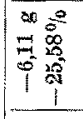 & & 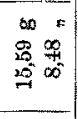 & $\begin{array}{l}\infty \\
=0 \\
=0 \\
10 \\
10 \\
0\end{array}$ & & 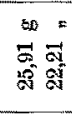 & $\begin{array}{ll}30 & 0 \\
8 & 8 \\
0 & 9 \\
0 & 4 \\
1 & 1 \\
\end{array}$ \\
\hline $\begin{array}{l}5 \\
8 \\
=\end{array}$ & 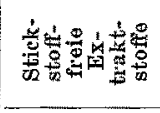 & 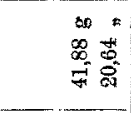 & 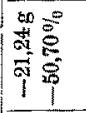 & & 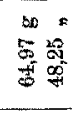 & 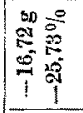 & & 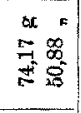 & 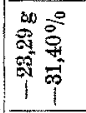 & & 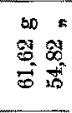 & 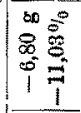 \\
\hline$\stackrel{\overrightarrow{0}}{\stackrel{\overrightarrow{0}}{ \pm}}$ & 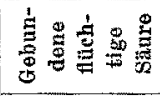 & 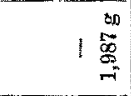 & 11 & & $1 \frac{5}{5}$ & 11 & & 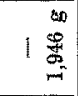 & 11 & & 18 & 11 \\
\hline 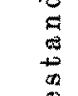 & 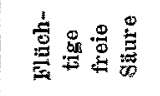 & 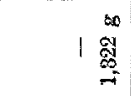 & 11 & & $\begin{array}{r}5 \\
1 \\
1 \\
3 \\
3 \\
-10\end{array}$ & 11 & & 19 & 11 & & 1 영 & 11 \\
\hline$\stackrel{\infty}{\approx}$ & 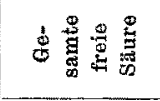 & 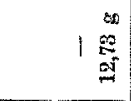 & 11 & & 19 & 11 & & 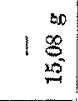 & 11 & & $\begin{array}{c}\infty \\
1 \\
0 \\
0 \\
\infty \\
\infty\end{array}$ & 11 \\
\hline$=$ & 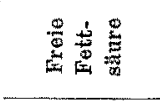 & $\begin{array}{r}5 \\
18 \\
10 \\
\infty \\
\infty\end{array}$ & 11 & & 180 & 11 & & 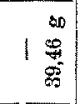 & 11 & & $1 \stackrel{60}{10}$ & 11 \\
\hline$\underset{\Xi}{ \pm}$ & 焉 & 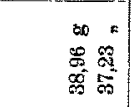 & 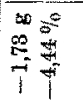 & & 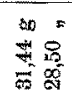 & 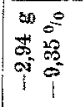 & & 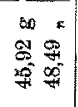 & 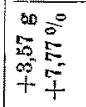 & & 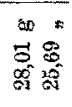 & 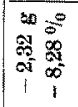 \\
\hline $\begin{array}{c}+\infty \\
0 \\
0\end{array}$ & 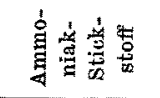 & 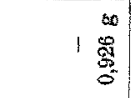 & 11 & & $1 \stackrel{s}{g}$ & 11 & & 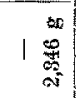 & 11 & & $1 \stackrel{8}{8}$ & 11 \\
\hline 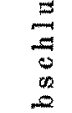 & 竞营 & 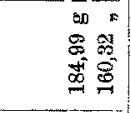 & 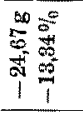 & & 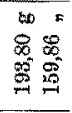 & 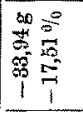 & & 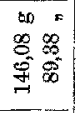 & 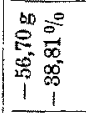 & & 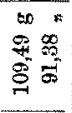 & 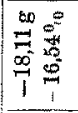 \\
\hline 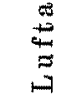 & 专 & 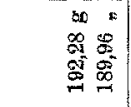 & 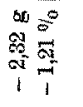 & & 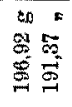 & 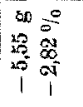 & & 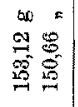 & $\begin{array}{ll}30 & 0 \\
0 & 0 \\
0 & 0 \\
0 & 0 \\
1 & 0 \\
1 & 1\end{array}$ & & 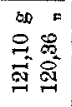 & 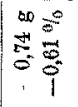 \\
\hline 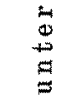 & 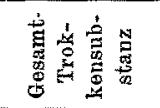 & 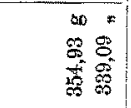 & 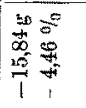 & & 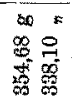 & 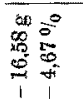 & & 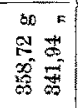 & 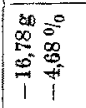 & & 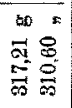 & 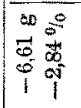 \\
\hline $\begin{array}{l}0 \\
0 \\
0 \\
0 \\
00 \\
0 \\
0 \\
0 \\
0 \\
0 \\
0 \\
\pm \\
0 \\
0 \\
0 \\
0 \\
0\end{array}$ & 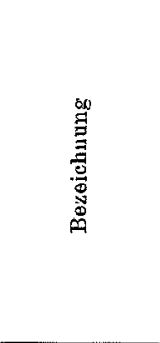 & 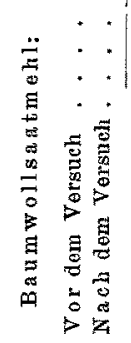 & 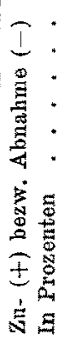 & 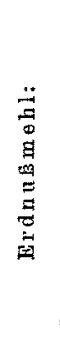 & 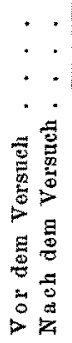 & 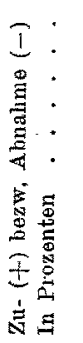 & 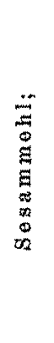 & 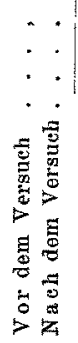 & 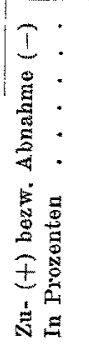 & 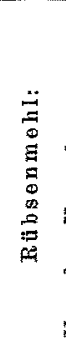 & 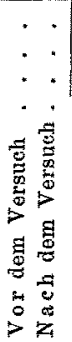 & 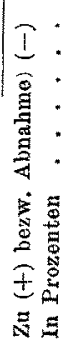 \\
\hline & $\bar{z}$ & $\rightarrow$ & & $\Leftrightarrow$ & & & $\infty$ & & & $H$ & & \\
\hline
\end{tabular}




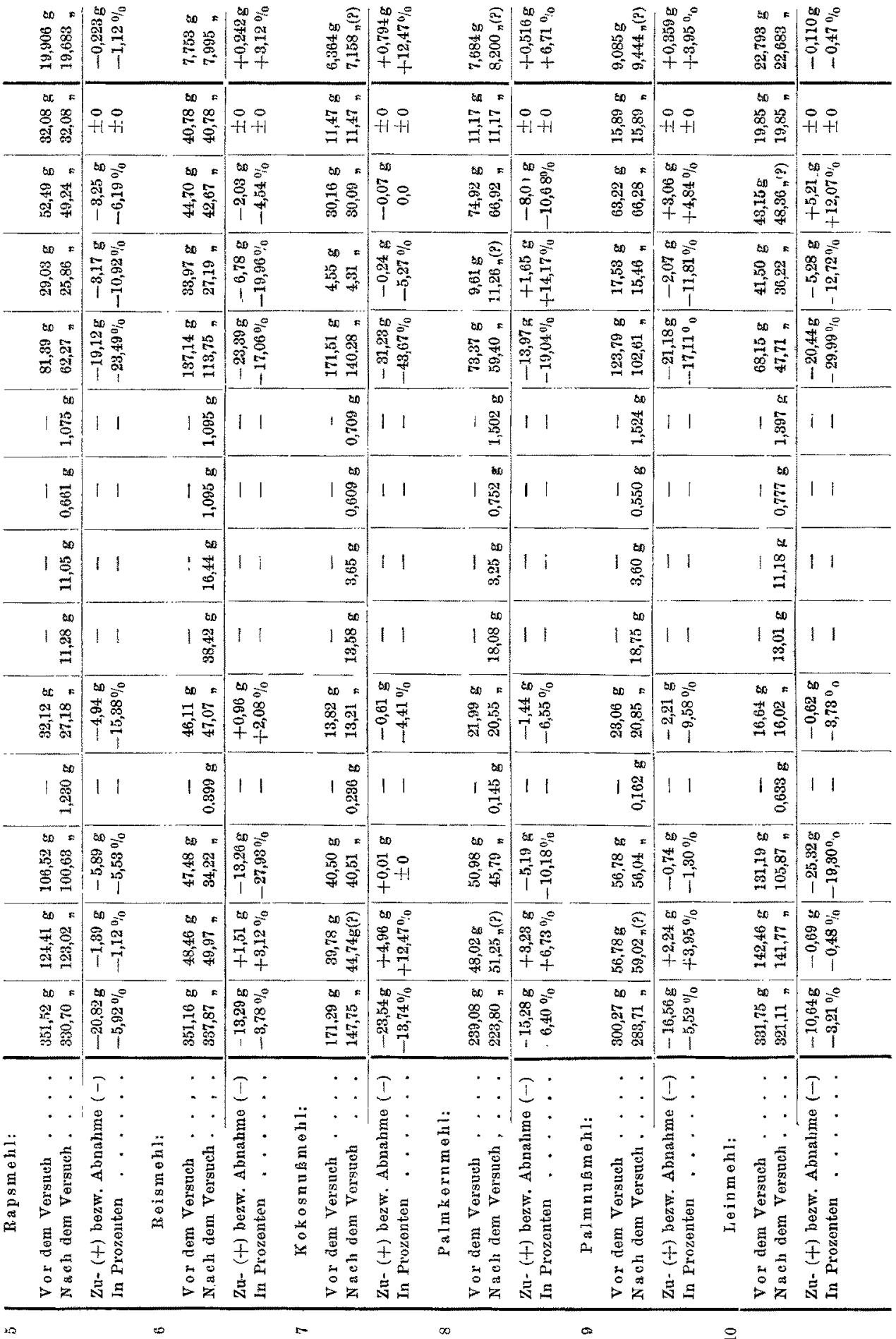


Zweite Versuchsreihe.

Freiwillige Zersetzung von Futtermitteln unter Mitwirkung der obligat anaëroben, Protein zersetzenden Bakterien.

Für diese Untersuchung wurden Lein-, Sesam-, Erdnuß- und Kokosnußmehl 9 bezw. letzteres 11 Monate lang in dünner Schicht von etwa $5 \mathrm{~cm}$ Dicke faulen gelassen, wobei monatelang die Flora im Innern fast lediglich aus Anaërobiern und in den äußeren Schichten aus Kartoffelbacillen beständ. Die Schimmelschicht war, nachdem die Rinde alkalisch geworden, verschwunden.

Die Untersuchungsergebnisse sind in den Tabellen IV und V zusammengestellt.

Tabelle IV.

Zusammensetzung und Umsetzung der bei Luftzutritt 9 Monate lang gefaulten Mehle.

A. Prozentuale Zusammensetzung der Trockensubstanz:

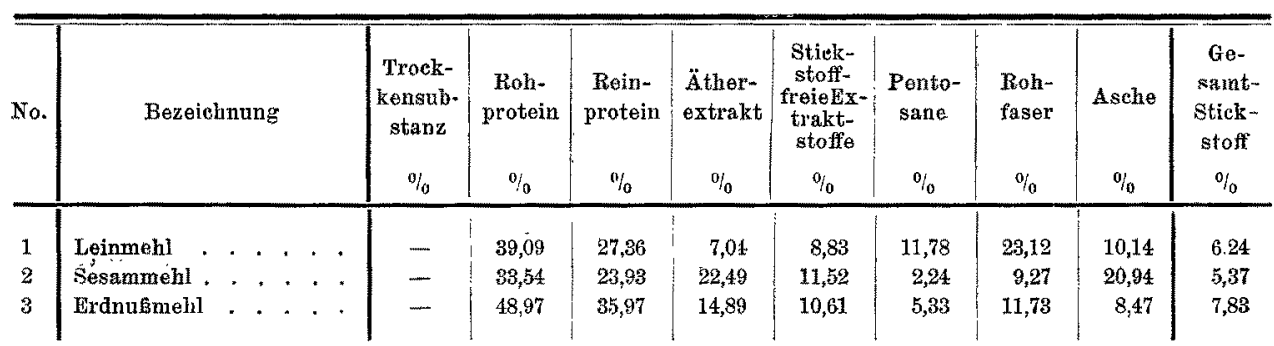

B. Absolute Mengen vor ${ }^{1}$ ) und nach $^{2}$ ) dem Versuch:

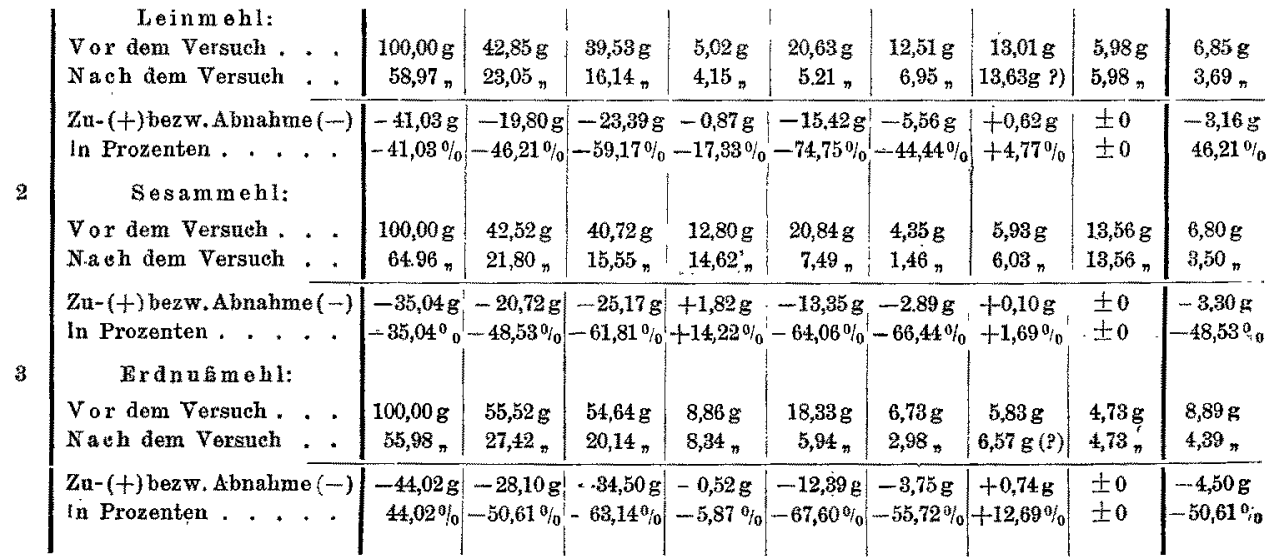

1) Berechnet nach Tabelle I (S. 188) anf $100 \mathrm{~g}$ Trockensubstanz.

2) Berechnet nach obigen Zahlen unter Voraussetzung eines unveränderten Aschengehaltes. 
Tabelle V.

Znsammensetzung und Umsetzung des bei Laftzutritt 11 Monate lang gefaulten Kokosnubmehles vor und nach dem Versuche.

A. Prozentuale Zusammensetzung der Trockensubstanz:

\begin{tabular}{|c|c|c|c|c|c|c|c|c|c|}
\hline Kokosnufmehl & $\begin{array}{c}\text { Ge- } \\
\text { samte } \\
\text { feuchte } \\
\text { Masse }\end{array}$ & $\begin{array}{l}\text { Trok- } \\
\text { kensub- } \\
\text { stanz }\end{array}$ & $\begin{array}{c}\text { Roh- } \\
\text { protein }\end{array}$ & $\begin{array}{c}\text { Rein- } \\
\text { protein }\end{array}$ & $\begin{array}{l}\text { ather- } \\
\text { extrakt }\end{array}$ & $\begin{array}{c}\text { Stick- } \\
\text { stoff- } \\
\text { freielix. } \\
\text { trakt- } \\
\text { stoffe }\end{array}$ & $\begin{array}{l}\text { Roh- } \\
\text { faser }\end{array}$ & $\begin{array}{c}\text { Pento- } \\
\text { sane }\end{array}$ & Astehe \\
\hline $\begin{array}{l}\text { Vor dem Versueh. } \\
\text { Nach dem Versuch. }\end{array}$ & - & $\begin{array}{l}41,40 \% \\
15,84,\end{array}$ & $\begin{array}{l}23,64 \% \\
21,74\end{array}$ & $\begin{array}{l}23,22 \% \\
19,04,\end{array}$ & $\begin{array}{l}8,07 \% \\
13,75\end{array}$ & $41 \underbrace{, 39 a^{40}}_{36,38}$ & $\frac{17,61}{8 \%} \%$ & $\begin{array}{l}2,60 \% \\
5,96\end{array}$ & $\begin{array}{r}6,890 \\
21,87\end{array}$ \\
\hline
\end{tabular}

B. Absoluie Mengen vor und nach dem Versuch:

\begin{tabular}{|c|c|c|c|c|c|c|c|c|}
\hline $\begin{array}{l}\text { Vor dem Versuch } \\
\text { Nach dem Versuch. }\end{array}$ & $\begin{array}{l}4400 \mathrm{~g} \\
3375 \mathrm{~m}\end{array}$ & $\begin{array}{r}1821,0 \mathrm{~g} \\
334,7\end{array}$ & $\begin{array}{l}430,48 \mathrm{~g} \\
116,24\end{array}$ & $\begin{array}{l}422,83 \mathrm{~g} \\
101,81\end{array}$ & $\begin{array}{r}146,95 \mathrm{~g} \\
73,52\end{array}$ & $\begin{array}{r}1077,30 \mathrm{~g} \\
19 \mathrm{~s}, 13\end{array}$ & $\begin{array}{l}48,449 \\
31,87,\end{array}$ & $\begin{array}{l}121,92 \mathrm{~g} \\
116,94 \text {, }\end{array}$ \\
\hline $\begin{array}{c}\mathrm{Zn}-(+) \text { bezw. Ab- } \\
\text { nalme }(-) . \\
\text { In Prozenten }\end{array}$ & $\begin{array}{r}-10.5 \mathrm{~g} \\
-23,27 \%\end{array}$ & $\begin{array}{l}-1286,3 g \\
-70,69 \%\end{array}$ & $\begin{array}{l}-314,24 g \\
-73,00 \%\end{array}$ & $\begin{array}{l}-321,02 \mathrm{~g} \\
-75,92 \%\end{array}$ & $\begin{array}{l}-73,43 \mathrm{~g} \\
-49,9790\end{array}$ & $\begin{array}{l}-881,17 \mathrm{~g} \\
-81,80 \%\end{array}$ & $\begin{array}{l}-16,57 \mathrm{~g} \\
-34,21 \%\end{array}$ & $\begin{array}{r}-4,88 \mathrm{~g} \\
-4,01 \%\end{array}$ \\
\hline
\end{tabular}

Aus den Tabellen IV und $\mathrm{V}$ geht hervor, daß unter der vereinigten Wirkung dieser beiden proteinzersetzenden Bakteriengruppen bis zu $70 \%$ der Trockenmasse verschwunden waren. Den Hauptverlust erlitten auch in diesem Falle die stickstofffreien Extraktstoffe, die bis 90\% ihrer Menge einbüßten. Ebenso nahmen die Pentosane erheblich ab, während Rohfaser und Fett bei Lein-, Sesam- und Erdnufmehl keine Einbuße erlitten hatten. Deshalb wurde die Rohfaserbestimmung bei Kokosnußmehl nicht ausgeführt, zumal da gerade bei diesem Mehle gut übereinstimmende Ergebnisse kaum erzielt wurden; es wurden hier vielmehr Rohfaser und stickstofffreie Extraktstoffe aus der Differenz berechnet. Die starke Abnabme des Ätherextraktes beim Kokosnußmehl erkläri sich vielleicht so, daß das Fett zum großen Teil gespalten und die Säuren durch das gebildete Ammoniak in ätherunlösliche Salze übergeführt worden waren. Sehr stark war bei allen Mehlen der Rückgang des Reinproteins, der bis über $70 \%$ betrug. Eine starke Einbuße hatte auch der Gesamtstickstoff erlitten, hauptsächlich wohl durch Ammoniakverdunstung.

Dritte Versuchsreihe.

Zersetzung von sterilisiertem Baumwollsatmehl durch Bacillus putrifieus.

Um die Einwirkung des Bacillus putrificus, der, wie aus dem bakteriologisehen Teile hervorgeht, der hauptsächlichste anaërobe Proteinzersetzer in den untersuchten Futter-

N. 0 . 
mehlen ist, auch für sich auf eines der Futtermittel kennen zu lernen, wurde er in sterilisiertes Baumwollsaatmehl geimpft und dieses in einer durch Pyrogallussäure von Sauerstoff befreiten Atmosphäre gehalten. Die Aufarbeitung der Probe erfolgte nach acht Wochen. Die Probe war nach dieser Zeit äuBerlich unverändert, reagierte und roch sauer und etwas aromatisch, aber nicht faul. Die hakteriologische Untersuchung ergab die Anwesenheit des Bacillus putrifieus in Reinkultur. Über die stattgehabte Zersetzung geben die folgenden Ubersichten Aufklärung:

A. Prozentuale Zusammensetzung des sterilisierten Baumollsatamehles vor und nach dem Versuche.

\begin{tabular}{|c|c|c|c|c|c|c|c|c|c|c|}
\hline Bezeichnung & $\begin{array}{c}\text { Wasser } \\
0_{i 0} \\
\end{array}$ & $\left\{\begin{array}{c}\text { Roh- } \\
\text { protein } \\
\% \\
\end{array}\right.$ & $\begin{array}{c}\text { Rein. } \\
\text { protein } \\
0 / 6\end{array}$ & $\mid \begin{array}{c}\text { Äther- } \\
\text { extrakt } \\
0 \\
0\end{array}$ & 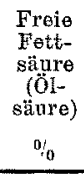 & $\begin{array}{c}\text { Stick- } \\
\text { stoff- } \\
\text { freiekx- } \\
\text { trakt- } \\
\text { stoffe } \\
0 \% \\
0\end{array}$ & $\begin{array}{c}\text { Pento- } \\
\text { sane } \\
\% \\
\end{array}$ & $\begin{array}{c}\text { Roh- } \\
\text { faser } \\
\% \\
\end{array}$ & $\begin{array}{l}\text { Asthe } \\
\% \\
\end{array}$ & $\begin{array}{c}\text { Ge- } \\
\text { samt- } \\
\text { Stiek- } \\
\text { stoff } \\
\% \\
\end{array}$ \\
\hline $\begin{array}{l}\text { a) Natürliche Sub } \\
\text { stanz: }\end{array}$ & & & & & & & & & & \\
\hline Vor dem Versuch & 57,14 & 28,45 & 22,03 & 4,81 & 0,70 & 5,59 & 3,23 & 3,36 & 2,90 & 3.75 \\
\hline $\begin{array}{c}\text { Nach dem Versuch } \\
\text { b) Trockensub- } \\
\text { stanz: }\end{array}$ & 56,75 & 23,31 & 15,64 & 5,55 & 4,67 & 3,84 & 8,41 & 4,08 & 3,06 & 3,73 \\
\hline Vor dem Versuch & - & 54.76 & 51,44 & 10,06 & 1,64 & 12,95 & 7,60 & 7,85 & 6,78 & 8,76 \\
\hline Nach dem Versuch & - & 53.75 & 86,04 & 12,79 & 10,77 & 9,13 & 7,87 & 9,41 & 7,05 & 8,60 \\
\hline
\end{tabular}

B. Absolute Mengen vor und nash dem Versuch.

\begin{tabular}{|c|c|c|c|c|c|c|c|c|c|c|c|}
\hline Bezeiehnung & $\begin{array}{c}\text { Ge- } \\
\text { samte } \\
\text { ferchte } \\
\text { Masse } \\
\mathrm{g}\end{array}$ & $\begin{array}{c}\text { Ge.. } \\
\text { Sante } \\
\text { Trok- } \\
\text { kensub- } \\
\text { stanz } \\
\mathrm{g}\end{array}$ & $\mid \begin{array}{c}\text { Roh- } \\
\text { protein } \\
\mathrm{g}\end{array}$ & $\begin{array}{c}\text { Rein- } \\
\text { protein } \\
g\end{array}$ & $\begin{array}{c}\text { Äther- } \\
\text { extrakt } \\
\mathrm{g}\end{array}$ & $\begin{array}{c}\text { Freie } \\
\text { Fett. } \\
\text { säyren } \\
\text { (ôl- } \\
\text { săur } \theta) \\
g\end{array}$ & $\begin{array}{c}\text { Stick- } \\
\text { stoff- } \\
\text { freieEz- } \\
\text { trakt- } \\
\text { stoffe } \\
\mathrm{g}\end{array}$ & $\begin{array}{l}\text { Pente- } \\
\operatorname{san} \theta \\
\mathrm{g}\end{array}$ & $\begin{array}{l}\text { Roh- } \\
\text { faser } \\
\mathrm{g}\end{array}$ & $\begin{array}{l}\text { Asehe } \\
g\end{array}$ & $\begin{array}{l}\text { Ge. } \\
\text { sant- } \\
\text { Stick- } \\
\text { stoff } \\
\text { g }\end{array}$ \\
\hline $\begin{array}{l}\text { Vor dem Versueh } \\
\text { Nach dem Versuch }\end{array}$ & $\begin{array}{l}700,0 \\
677,0\end{array}$ & $\begin{array}{l}300,0 \\
292,8\end{array}$ & $\begin{array}{l}164,15 \\
157,81\end{array}$ & $\begin{array}{l}15 \pm, 21 \\
105,88\end{array}$ & $\begin{array}{l}30,17 \\
37,57\end{array}$ & $\begin{array}{r}4,90 \\
31,62 \\
\end{array}$ & $\begin{array}{l}39,11 \\
25,99\end{array}$ & $\begin{array}{l}29,75 \\
23,09\end{array}$ & $\begin{array}{l}23,52 \\
27,62 \\
\end{array}$ & $\begin{array}{l}20,30 \\
20,72 \\
\end{array}$ & $\begin{array}{l}26,26 \\
25,25 \\
\end{array}$ \\
\hline $\begin{array}{l}\mathrm{Zu}-(+) \text { bezw, } \mathrm{Ab} \text {. } \\
\text { nahme }(-) . \\
\text { In Prozenten. . }\end{array}$ & $\begin{array}{l}-28,0 \\
-3,29\end{array}$ & $\begin{array}{l}-7,2 \\
-240\end{array}$ & $\begin{array}{l}-6,34 \\
-3,83\end{array}$ & $\begin{array}{r}-48,33 \\
-3,13\end{array}$ & $\begin{array}{r}+7,40 \\
+24,58\end{array}$ & $\begin{array}{r}+26,72 \\
+545,31\end{array}$ & $\begin{array}{l}-13,12 \\
-83,55\end{array}$ & $\begin{array}{l}+0,84 \\
+1,50\end{array}$ & $\begin{array}{r}+4,10 \\
+17,42\end{array}$ & $\begin{array}{l}+0,42 \\
+2,07\end{array}$ & $\begin{array}{l}-1,01 \\
-3,85\end{array}$ \\
\hline
\end{tabular}

Die Zahlen zuigen, daß auffallenderweise Bacillus putrificus die Proteinstoffe nicht oder kaum verändert, sondern nur eine stärkere Abnahme der stickstofffreien Extraktstoffe bewirkt hat. Im Zusammenhang nit der sauren Reaktion muß man infolge der starken Zunahme des Ätherextraktes und der freien Säuren annehmen, daß lediglich eine Vergärung des Zuckers vor sich gegangen ist und daß unter den gewählten Versuchsbedingungen Bacillus putrificus überhaupt keine, oder doch keine wesentliche Verände- 
rung der Proteinstoffe herbeizuführen vermag. Diese Annahme haben wir durch Versuche mit Eiereiweif bei Gegenwart von Zuckern bestätigen können, bei denen sich aber zeigte, daß auch die Art des Zuckers von ausschlaggebender Bedeutung ist. Röhrchen mit Bouillon und 3\%-igem Peptonwasser in hoher Schicht wurden ohne und mit Zusatz von $2 \%$ und $5 \%$ Glykose, Fruktose, Galaktose, Saccharose, Maltose, Laktose, Mannit und Glycerin sterilisiert, mit Bacillus putrificus aus gefaultem Baumwollsaatmehl und dem Stamme der Sammlung Krâl geimpft und in einer Wasserstoffatmosphäre, bezw. mit einer sterilisierten Ölschicht bedeckt, bei $34^{0}$ stehen gelassen. Jedes Röhrchen enthielt einen Würfel gekochtes Eieralbunin. Außer in der Glycerinlösung wuchsen die Bakterien überall; die Einwirkung war aber ganz verschieden. In den Lösungen ohne Zucker, sowie in denen mit Saccharose und Mannit war das Eiweil nach kurzer Zeit verschwunden. Die Lösungen reagierten alkalisch und zeigten starken Fäulnisgeruch. In den Laktoselösungen war das Eiweiß nach mehreren Wochen zwar nicht ganz verschwunden, aber stark vermindert. Die Reaktion war neutral bis schwach alkalisch. In allen anderen Lösungen blieb das Eiweiß äußerlich unverändert; die Reaktion war in ihnen stark sauer; Fäulnisgeruch fehlte. Die starke Gasentwickelung zu Anfang und der dicke Bodensatz von Bakterien, der hier, wie in den alkalischen Lösungen eine Unmenge Sporangien aufwies, zeigten, daß eine Vermehrung der Bakterien stattgefunden hatte. Es scheint also, daß Bacillus putrificus gegenüber verschiedenen Zuckerarten ein verschiedenes Gärvermögen besitzt, und daß es von ihnen abhängt, $\mathrm{ob}$ er gleichzeitig gebotene Proteinstoffe zersetzt. Daß die Laktose nicht hemmend wirkt, zeigt auch das Verhalten der Bakterien in Milch, die von ihnen unter fast völliger Lösung des Kaseins zu einer stinkenden, durchsichtigen, gelben Flüssigkeit zersetzt wird.

Die hemmende Wirkung der Zuckerarten muß höchst wahrscheinlich auf die Entstehung von Gärungssäuren zurückgeführt werden, die die Wirkung des Trypsins abschwächen, vielleicht auch seine Ausscheidung später ganz verhindern. Eine Abscheidung von proteolytischen Enzymen findet auch bei Gegenwart von gärfähigem Zucker statt, wie der folgende Versuch beweist. Kölbchen mit je $50 \mathrm{ccm}$ Nährlösung (1 Teil Bouillon, 3 Teile Wasser, 0,1\% primäres Kaliumphosphat, 0,05\% Magnesiumsulfat mit Soda neutralisiert), $15 \mathrm{~g}$ gekochtes, gehacktes Hühnereiweib, ohne und mit $1 / 2,1,2$ und $5 \%$ Glykose wurden mit Bacillus putrificus geimpft und bei $34^{0}$ in einer Wasserstoffatmosphäre vierzehn Tage lang stehen gelassen. Nach dieser Zeit ergab sich folgendes Bild:

$\begin{array}{cccc}\text { Zuckergehalt } & \text { Reaktion } & \text { Geruch } & \begin{array}{c}\text { Verhaltendes } \\ \text { Eiweilses }\end{array} \\ 0 & \text { stark alkalisch } & \text { faulig } & \begin{array}{c}\text { ganz zersetzt } \\ \text { fast ganz zersetzt }\end{array} \\ 0,5 \% & \text { schwach alkalisch } & * & \text { stark zersetzt } \\ 1 \% & \text { neutral bis schwach sauer } & - & - \\ 2 \% & \text { sauer } & - \\ 5, & \% & \text { Jicht merklich zersetzt }\end{array}$

Die chemische Analyse ergab folgende Mengen gelösten und nicht gelösten Stick- 


\begin{tabular}{|c|c|c|c|c|c|c|}
\hline \multirow{4}{*}{$\begin{array}{l}\text { Gelöster Stickstoff. } \\
\text { Stickstoff im Rückstande }\end{array}$} & \multicolumn{5}{|c|}{ Zuckergehalt: } & \multirow[b]{2}{*}{ ungeimpft } \\
\hline & 0 & $0,5 \%$ & $1 \%$ & $2 \%$ & $5 \%$ & \\
\hline & $0,275 \mathrm{~g}$ & $0,215 \mathrm{~g}$ & $0,176 \mathrm{~g}$ & $0,129 \mathrm{~g}$ & $0,106 \mathrm{~g}$ & $0,047 \mathrm{~g}$ \\
\hline & 0,019 & 0,061 & 0,094 & $0,13 ?$ & 0,173 & 0,247 \\
\hline & $0,294 \mathrm{~g}$ & $\begin{array}{c}0,276 \mathrm{~g} \\
\text { oder in } \mathrm{F}\end{array}$ & $\begin{array}{l}0,270 \mathrm{~g} \\
\text { zenten }\end{array}$ & $0,267 \mathrm{~g}$ & $0,279 \mathrm{~g}$ & $0,294, \mathrm{~g}$ \\
\hline Gelöster & $98,5 \%$ & $77,9 \%$ & $65,2 \%$ & $48,4 \%$ & $38,0 \%$ & $16,0 \%$ \\
\hline Stickstoff im Rückstande & 6,5 , & 22,1 & 34,8, & 51,6 & 62,0 & 84,0 \\
\hline
\end{tabular}

Aus diesen Versuche geht klar hervor, daß auch die Anwesenheit eines gärfähigen Zuckers in kleinen Mengen die Abscheidung von proteolytischem Enzym nicht verhindert, und daß Zuckergärung uńd Proteinzersetzung gleichzeitig verlaufen können, daß letztere aber schon durch einen Zusatz von $2 \%$ Glykose sehr verlangsamt wird. Daß̊ die entstehende Säure und nicht etwa die höhere Konzentration der Zuckerlösung auf Ausscheidung und Wirkung des proteolytischen Enzyms hemmend wirkt, hätte am besten durch Neutralisierung der Gärungssäuren festgestellt werden können. Es ist uns aber nicht gelungen, dureh Zusatz von Kohlensaurem Kalk zu den Nährlösungen die Neutralisierung der Säuren zu erzielen, da der Kohlensaure Kalk sich mit einer schleimigen Masse überzieht und nicht mehr verteilt werden kann. Neutralisierung durch Vergärung von Harnstoff durch den Bacillus putrificus, wie sie Tissier und $M a r t e l l y^{1}$ ) bei ähnlichen Versuchen angewendet haben, ist uns nicht gelungen, da unsere Kulturen in harnstoffhaltigen Lösungen nicht wuchsen.

Aus diesen Versuchen erklärt sich auch das Verhalten des Bacillus putrificus gegen sterilisiertes Baumwollsaatmehl unter der Annahme, daß die in ihm enthaltene Raffinose (Gossypose), die jedenfalls durch das mehrmalige Sterilisieren unter Druck auch wenigstens teilweise hydrolisiert worden war, dem Bacillus wohl ihre Vergårung, nicht aber die Zersetzung der Proteinstoffe gestattete, besonders da ihre Menge den Zuckergehalt der angewendeten Nährlösungen erheblich übersteigt.

Unter den verschiedenen aus den faulen Futtermitteln gezüchteten Stämmen des Bacillus putrificus haben wir keinen gefunden, der sich gegen Zucker anders verhalten hätte. Natürlich ist es nicht ausgeschlossen, daß auch Stämme vorkommen können, deren Gärvermögen so gering ist, daß sie auch in stark zuckerhaltigen Nährböden die Proteinstoffe wesentlich zu zersetzen vermögen. Diese würden dann auch sterilisiertes Baumwollsaatmehl zersetzen können.

Um zu zeigen, daß auch bei der freiwilligen Zersetzung unter Luftabschlub in der Tat nur die bei der Vergärung der Kohlenhydrate dureh die Kokken und Stäbchenbakterien entstehenden Säuren die Entwickelung des Bacillus putrificus hemmen, wurden verschiedene Futtermittel unter Zusatz erheblicher Mengen von Kohlensaurem Kalk acht Monate unter Luftabschluß faulen gelassen. Es zeigte sich aber auch hier, daß trotz dieser Maßregel die Säure nicht inmer völlig neutralisiert wird. Das verwendete Reismebl war noch sauer, Baumwollsaat-, Lein- und Kokosnußmehl ehen neutral. Obligate Anaërobier waren nicht zur Eutwickelung gekommen, sondern nur Kokken und Stäbchen der Koli-Gruppe. Nur das Kokosnufomehl enthielt Buttersäurebakterien. Eine stinkende Fäulnis war nicht eingetreten, doch zeigte das Reinprotein eine viel stärkere Zersetzung als bei den früheren Versuchen ohne Zusatz von Kohlensaurem Kalk, wie aus nachstehender Tabelle hervorgeht:

1) Ann. Instit. Pasteur 1902, 16, 865. 


\begin{tabular}{|c|c|c|c|c|c|c|c|c|}
\hline \multirow{3}{*}{ No. } & \multirow{3}{*}{ Bezeichnung des Mehles } & \multicolumn{3}{|c|}{ In Prozenten: } & \multicolumn{4}{|c|}{ In absoluten Mengen (Gramm): } \\
\hline & & \multirow{2}{*}{$\begin{array}{l}\text { Trok- } \\
\text { kensub- } \\
\text { stanz }\end{array}$} & Roh- & Rein- & \multirow[b]{2}{*}{ Gesamut-Masse } & \multirow{2}{*}{$\begin{array}{r}\text { Trok- } \\
\text { kensub } \\
\text { stanz }\end{array}$} & \multirow[b]{2}{*}{$\begin{array}{c}\text { Roh- } \\
\text { protein }\end{array}$} & \multirow[b]{2}{*}{$\begin{array}{c}\text { Rein- } \\
\text { protein }\end{array}$} \\
\hline & & & \multicolumn{2}{|c|}{$\begin{array}{l}\text { protein in der } \\
\text { Troutkensub- } \\
\text { stanz des Mebles }\end{array}$} & & & & \\
\hline \multirow{5}{*}{1} & \multirow{5}{*}{$\begin{array}{l}\text { Baumwollsaat. } \\
\text { mehl: } \\
\text { Vor dem Versuch }) \\
\text { Nach dem Versuch }\end{array}$} & \multirow{5}{*}{$\begin{array}{l}90,20 \\
57,67\end{array}$} & \multirow{5}{*}{$\begin{array}{l}54,20 \\
46,00\end{array}$} & \multirow{5}{*}{$\begin{array}{l}52,12 \\
40,81\end{array}$} & Mehl 300 & $\begin{array}{c}270,9 \\
75\end{array}$ & \multirow{4}{*}{$\begin{array}{l}146,8 \mathrm{~g} \\
119,6 \mathrm{~g}\end{array}$} & \multirow{4}{*}{$\begin{array}{l}141,2 \mathrm{~g} \\
106,1\end{array}$} \\
\hline & & & & & Wasser & - & & \\
\hline & & & & & 675 & 345,9 & & \\
\hline & & & & & 451 & 260,1 & & \\
\hline & & & & & $\begin{array}{l}\text { Abnahme (-) } \\
\text { In Prozenten. }\end{array}$ & $\begin{array}{l}\cdot \cdot \\
\cdot \cdot\end{array}$ & $\begin{array}{r}-27,2 \mathrm{~g} \\
-18,52 \%\end{array}$ & $\begin{array}{r}-35,1 \mathrm{~g} \\
-24,86 \%\end{array}$ \\
\hline \multirow{5}{*}{2} & \multirow{5}{*}{$\begin{array}{l}\text { Reismehl: } \\
\text { Vor dem Versuch }{ }^{1} \text { ) } \\
\text { Nach dem Versuch }\end{array}$} & \multirow{5}{*}{$\begin{array}{l}89,72 \\
61,71\end{array}$} & \multirow{5}{*}{$\begin{array}{l}13,80 \\
10,46\end{array}$} & \multirow{5}{*}{$\begin{array}{r}13,52 \\
7,81\end{array}$} & $\begin{array}{l}\text { Mehl } 300 \\
\text { Kohlens.Kalk } 75\end{array}$ & $\begin{array}{c}269,2 \\
75\end{array}$ & \multirow{4}{*}{$\begin{array}{l}37,1 \mathrm{~g} \\
30,6,\end{array}$} & \multirow{4}{*}{$\begin{array}{l}36,4 \mathrm{~g} \\
22,8\end{array}$} \\
\hline & & & & & Wasser & - & & \\
\hline & & & & & 675 & 344,2 & & \\
\hline & & & & & 474 & 292,5 & & \\
\hline & & & & & $\begin{array}{l}\text { Abnahme (-) } \\
\text { In Prozenten . }\end{array}$ & $\begin{array}{ll}\cdot & \cdot \\
. & . \\
.\end{array}$ & $\begin{array}{c}-6,5 \mathrm{~g} \\
-17,52 \% \%\end{array}$ & $\begin{array}{r}-13,6 \mathrm{~g} \\
-37,36 \%\end{array}$ \\
\hline \multirow{4}{*}{3} & \multirow{4}{*}{$\begin{array}{l}\text { Leinmehl: } \\
\text { Vor dem Versuch }{ }^{1} \text { ) } \\
\text { Nach dem Versuch }\end{array}$} & \multirow{4}{*}{$\begin{array}{l}90,10 \\
42,66\end{array}$} & \multirow{4}{*}{$\begin{array}{l}42,85 \\
34,69\end{array}$} & \multirow{4}{*}{$\begin{array}{l}39,53 \\
25,92\end{array}$} & $\begin{array}{l}\text { Mehl } \quad 300 \\
\text { Kohlens.Kalk } 75\end{array}$ & $\begin{array}{c}270,3 \\
75 \\
-\end{array}$ & \multirow{3}{*}{$\begin{array}{l}115,8 \mathrm{~g} \\
106,8\end{array}$} & \multirow{3}{*}{$\begin{array}{r}106,9 \mathrm{~g} \\
79,8\end{array}$} \\
\hline & & & & & 825 & 345,3 & & \\
\hline & & & & & 722 & 308,0 & & \\
\hline & & & & & $\begin{array}{l}\text { Abnahme (-) } \\
\text { In Prozenten. }\end{array}$ & $\cdot$. & $\begin{array}{r}-9,0 \mathrm{~g} \\
-7,77 \%\end{array}$ & $\mid \begin{array}{r}-27,1 \mathrm{~g} \\
-25,53 \%\end{array}$ \\
\hline \multirow{5}{*}{4} & \multirow{5}{*}{$\begin{array}{l}\text { Kokosnukmehl: } \\
\text { Vor dem Versuch } \\
\text { Naeh dem Versuch }\end{array}$} & \multirow{5}{*}{$\begin{array}{l}88,02 \\
37,03\end{array}$} & & & $\begin{array}{l}\text { Mehl } 300 \\
\text { Kohlens.Kalk } 75\end{array}$ & $\begin{array}{c}264,1 \\
75\end{array}$ & & \\
\hline & & & & & Wasser & - & & \\
\hline & & & 23,64 & 23,22 & 925 & 389,1 & $62,4 \mathrm{~g}$ & $61,3 \mathrm{~g}$ \\
\hline & & & 18,95 & 16,04 & 655 & 242,6 & 46,0 , & 39,0 \\
\hline & & & & & $\begin{array}{l}\text { Abnahme (-) } \\
\text { In Prozenten. }\end{array}$ & $\begin{array}{l}. \\
.\end{array}$ & $\begin{array}{r}-16,4 \mathrm{~g} \\
-26,28 \%\end{array}$ & $\begin{array}{r}-22,3 \mathrm{~g} \\
-36,38^{\circ}, 0\end{array}$ \\
\hline
\end{tabular}

Die chemischen Untersuchungen der zersetzten Futtermittel haben also folgendes Endergebnis geliefert:

1. Die freiwillige Zersetzung der untersuchten Kraftfuttermittel verläuft qualitativ bei Abschluf und Zutritt des Sauerstoffes in derselben Richtung, unterscheidet sich quantitativ aber erheblich.

2. Der Verlust an Trockenmasse ist bei Luftabschluß sehr gering, bei Luftzutritt bei gleicher Dauer sehr erheblich.

3. Den Hauptanteil an dem Verlust tragen in beiden Fällen die stickstofffreien Extraktstoffe. Die Pentosane werden besonders bei Luftzutritt ebenfalls stark ver-

1) Vergleiche Tabelle I (S. 188). 
mindert, weniger bei Luftabschlaß. Die Rohfaser bleibt in wesentlichen unverändert, ebenso meist der Ätherextrakt.

4. Der Gesamt-Stickstoff orleidet merkliche Einbuße nur bei Luftzutritt. Das Reimprotein wird bei Luftabschluß nur in geringem Umfange, bei Luftzutritt zum größten Teil zu einfacheren Stickstoffverbindungen bis zu Ammoniak abgebaut.

5. Die Reaktion der zersetzten Futtermittel ist bei Luftabschluß stets stark sauer, ebenso der Geruch; bei Luftzutritt ist die Reaktion stark alkalisch, der Geruch widerlich faul. Farbe und Struktur bleiben bei Luftabschluf unverändert, gehen dagegen bei Luftzutritt völlig verloren.

\section{B. Untersuchungen über die Zersetzung von Proteinst of fen durch den aus ge- faultem Baumwollsaatmehl geztichteten Bacillus putrificus ${ }^{1}$ ).}

Diese Untersuchungen wurden mit Blutfibrin und Eiereiweiß angestellt.

a) Blutfibrin. Das Blutfibrin von der Firma F. Merck enthielt: $8,10 \%$ Wasser, 90,72\% Stickstoff-Substanz und 1,18\% Mineralstoffe.

Von dem grobzerkleinerten Blutfibrin wurde $1 / 2 \mathrm{~kg}$ in einem geräumigen Erlenmeyer-Kolben mit Wasser und $25 \mathrm{ccm}$ Fleischbrühe übersehichtet und mit aufgesetztem Wattepfropfen viermal $1 / 2$ Stunde bei $125^{\circ}$ im Autoklaven sterilisiert. Nach jeder Sterilisation wurde der Kolben 1-2 Tage bei Bruitemperatur stehen gelassen, um etwa noch vorhandene Sporen zur Entwickelung zu bringen und dann durch die folgende Sterilisation sicherer abzutöten. Darauf wurde der Inhalt des Kolbens vorsichtig mit sterilisiertem ÖI überschichtet, um auf diese einfache Weise einen luftdichten Abschlue herzustellen; dann wurde im Dampftopf bei $100^{\circ}$ aufgekocht. Auf gleiche Weise wurde noch ein zweiter Kolben mit $1 / 2 \mathrm{~kg}$ Blutfibrin hergerichtet; dieses wurde aber vorher fein gemahlen, um dadurch vielleicht eine stärkere Einwirkung des Bacillus zu erreichen.

Beide Kolben wurden mit dem aus dem gefaulten Baumwollsaatmehl gezüchteten Stamme des Bacillus putrificus geimpft und im Thermostaten bei $30-35^{\circ}$ faulen gelassen. Schon nach 48 Stunden entwickelten sich starke Gasblasen von äußerst unangenehmem Geruch, die mehrmals im Tage durch schwaches Neigen und Rollen der Kolben entfernt wurden. Nach 5 Wochen wurde der Inbalt beider Kolben aufgearbeitet.

Das OI wurde durch Auffüllen der Kolben mit sterilisiertem Wasser bis zum Überfließen des Öles entfernt, die letzten Spuren wurden mit Filtrierpapier abgetupft.

Das Blutfibrin war stark zersetzt, doch war noch ein ziemlich bedeutender braunschwarzer unzersetzter Rest verblieben; die überstehende Flüssigkeit roch äuBerst unan genehm und reagierte schwach alkalisch. Ein mikroskopisches Präparat zeigte ein einheitliches Bild von vielen Sporen und wenigen Stäbchen beim ersten Kolben, sowie von vielen Stäbchen, aber weniger Sporen beim zweiten Kolben, der mit dem feingemahlenen Blutfibrin beschickt war. Von dem Inhalte beider Kolben wurden auch aërobe Gelatine- und Agarkulturen angelegt, die aber kein Wachstum zeigten, während in einer anaëroben Kultur in hoher Schicht (Hochkultur) der Bacillus putrificus sich stark entwickelte.

1) Vergl. zu diesem Abschnitte: Hoppe-Seyler, Handbach der physiol. a. patholog. chemischen Analyse 1908, 7. Aufl, und E. Salkowski, Praktikum der physiol. a. patholog. Chemie 1900, 2. Aufl. 
Der Inhalt beider Kolben wurde durch ein Koliertuch gegeben, der Rückstand mit Wasser ausgewaschen, wieder in zwei Kolben verteilt, mit Wasser und etwas Fleischbrähe versetzt, sterilisiert und geimpft. Doch trat diesmal keine bemerkenswerte Gasbildung ein, ein Zeichen, daß die Fäulnis beim ersten Male einen Endzustand erreicht hatte, weshalb die Wiederholung des Versuches nicht weiter durchgeführt wurde.

Von der durchkolierten Flüssigkeit wurden $100 \mathrm{~cm}$ von Weizenkleie aufsaugen gelassen, der üble Geruch im Exsikkator über mit Kupfersulfat getränkten Bimssteinstäcken entfernt und dann an ein Kaninchen verfüttert. Es sollte dadurch festgestellt werden, ob nicht bei dieser starken Fäulnis sich giftige Stoffe gebildet hatten; doch war nach dem Verfüttern bei dem Kaninchen keinerlei schädliche Wirkung wahrzunehmen.

Der Rest der schwach alkalischen Flüssigkeit wurde noch mit $20 \mathrm{~g}$ Koblensaurem Natron versetzt, um alle Säuren sicher zu neutralisieren, und dann destilliert. Das zuerst übergehende Destillat wurde zum Nachweise von Merkaptan in einer $3 \%$-igen Lösung von Quecksilbercyanid aufgefangen. Der Niederschlag von Schwefelquecksilber und etwa gebildetem Merkaptanquecksilber wurde mit Salzsäure behandelt, worin sich letzteres löst, und die abtiltrierte Lösung in eine $3 \%$-ige Lösung von Bleiacetat destilliert. Es bildete sich an der Eintrittsstelle des Destillates ein schwaches gelbliches Häutchen, das sich beim Schütteln auflöste. Beim Verdunsten der Bleiacetatlösung hinterblieben neben rein weißen Krystallen von Bleiacetat wenige gelbliche Kryställchen, sodaß wenigstens Spuren von Methylmerkaptan als vorhanden angenommen werden können.

Das übrige Destillat der Fäulnisflüssigkeit wurde vorsichtig mit Schwefelsäure angesäuert und dann dreimal mit Äther ansgeschüttelt. Die wässerige Lösung wurde nicht weiter untersucht, während die Ätherlösung mit Natronlauge kräftig geschüttelt und von dieser getrennt wurde. Beim Abdunsten des Äthers zersprang leider der Kolben, wodurch der Nachweis des etwa vorhandenen Indols und Skatols unmöglich wurde.

Die Natronlauge wurde mit Schwefelsäure übersättigt, mit Natriumkarbonat wieder alkalisch gemacht, abermals mit Äher ausgeschüttelt und dieser von der wässerigen Lösung (a) getrennt. Beim Verdunsten des Äthers blieb ein ganz geringer Rückstand, der aber weder den eigenartigen Kresolgeruch zeigte, noch eine qualitative Reaktion auf Phenol oder Kresol gab.

Der ursprüngliche alkalische Destillationsrückstand wurde auf dem Wasserbade schwach eingeengt, mit etwa der zehnfachen Menge $95 \%$-igem Alkohol gefällt und abfiltriert. Der Rückstand, bestehend aus Fiweiß, Salzen und Bakterien, wurde unberücksichtigt gelassen. Das Filtrat wurde eingedampft, mit Alkohol aufgenommen, der Alkoholauszug mit der vorher erhaltenen wässerigen Lösung (a) vereinigt und bei alkalischer Reaktion eingedampft. Der Rückstand wurde mit Wasser aufgenommen, mit Schwefelsäure stark übersättigt und mehrmals mit Äther ausgeschüttelt.

In der wässerigen Lösung wurden Peptone durch die Biuretreaktion nachgewiesen. Der Ätherauszug wurde abgedunstet, mit verdünnter Natronlauge aufgenommen, mit Baryumchlorid zur Entfernung von Fett gefällt, filtriert, das Filtrat eingeengt, mit Salzsäure angesäuert und mit Äther ausgeschüttelt. Beim Verdunsten des Äthers hinterblieb ein schwer bewegliches Öl. Aus diesem wurden die flüchtigen Fettsäuren im Dampfstrome abdestilliert und in Natronlauge aufgefangen. Die Destillation 
wurde etwa 25 Stunden fortgesetzt, bis die übergehende Flüssigkeit nicht mehr sauer reagierte.

Die gesamte Destillationsflïssigkeit wurde eingedampft, mit Schwefelsäure übersättigt und mit $\ddot{A}$ ther gut ausgeschüttelt und dieser verdunstet.

Da bei der fraktionierten Destillation des Ätherrückstandes keine konstanten Siedepunkte erzielt werden konnten, wurden die einzelnen nicht scharf getrennten Fraktionen mit sorgfältig gereinigtem und von Chloriden befreitem Calciumkarbonat eingedampft. Die fettsauren Kalksalze wurden in viel kochendem Wasser gelöst und die Filtrate der fraktionierten Krystallisation unterworfen. Die erhaltenen Krystalle wurden im Exsikkator über Phosphorsäureanhydrid, unter gleichzeitigem Evakuieren und Erhitzen auf $70-80^{\circ}$, getrocknet, dann durch Glühen in Calciumoxyd umgewandelt und so ihr Calciumgehait festgestellt. So wurde bei verschiedenen Krystallfraktionen:

Gefunden
18,$17 ; 18,22 ; 18,47 \%$ Ca.
$16,33, "$,
13,$92 ; 15,32 \% "$
$11,96 \% "$

Berechnet für
Buttersaures Calcium $=18,72^{\circ} \% \mathrm{Ca}$.
Valeriansaures Calcinm $=16,56, "$
Kapronsaures Calcium $=14,84, "$
Kaprylsaures Calcium $=12,29, "$,

Phenylessigsäure und Phenylpropionsäure konnten in diesen Dampfstromdestillat nicht nachgewiesen werden.

Der im Destillationskolben verbliebene Rückstand wurde nach längerem Stehen von der abgeschiedenen harzigen Masse abfiltriert, das Filtrat eingeengt, wobei es sich violett färbte von einem Farbstoffe, der sich beim Erkalten in schleimiger Form mit dunkel gefärbten Krystallen abschied. Um diesen zu entfernen, wurden die Krystalle wieder gelöst und die Flüssigkeit mit Tierkohle gründlich ausgekocht. Aus dem so entfärbten Filtrate schieden sich nach mehrtägigem Stehen schwach rosa gefärbte Krystalle aus, die den Schmelzpunkt $129^{\circ}$ zeigten. Diese wurden in heißem Wasser gelöst und nochmals mit Tierkohle entfärbt, worauf rein weiße Nadeln und Tafeln auskrystallisierten, die den Schmelzpunkt $128^{\circ}$ zeigten, der für p-Oxyphenylpropionsäure stimmen würde, für die in der Literatur $125^{\circ}$ bezw. $128^{\circ}$ als Schmelzpunkt angegeben ist. Auch gab eine Spur der Krystalle, in wenig heißem Wasser gelöst, mit Millons Reagens beim Erwärmen eine sehr starke Rotfärbung. Skatolessigsäure, deren Schmelzpunkt zu $134^{\circ}$ angegeben ist, konnte es nicht sein, da die Krystalle keinen Stickstoff enthielten.

Aus der Mutterlauge dieser ersten Krystallisation wurden noch zwei weitere Körper vom Schmelzpunkt $127^{\circ}$ bezw. $124,5^{\circ}$ erhalten, worauf noch wenig schmieriges Ol zurückblieb, das auf keine Weise krystallinisch zu erhalten war, jedoch beim Erwärmen mit Millons Reagens noch starke Rotfärbung zeigte. Als Fäulniserzeugnisse des Blutfibrins wurden durch diesen Versuch also nachgewiesen: neben Sch wefelwasserstoff Spuren von Methylmerkaptan; an Fettsäuren: Butter-, Valerian-, Kapron- und Kaprylsäure; ferner p-Oxyphenylpropionsäure.

b) Eier-Albumin. Hiermit wurde die gleiche Untersuchung angestellt. Das gepulverte Eier-Albumin des Handels enthielt 14,13\% Wasser, 76,47\% StickstoffSubstanz und $4,51 \%$ Mineralstoffe.

$400 \mathrm{~g}$ dieses Albumins wurden in einem Erlenmeyer-Kolben mit stark verdünnter Bouillon überschichtet und bei $125^{\circ} \mathrm{im}$ Autoklaven $1 / 2$ Stunde sterilisiert. Da die ganze Masse sich dabei zu käseartiger Konsistenz zusammenballte, so wurde sie in kleine Würfel zerschnitten, in einen sterilisierten Kolben gefüllt, mit 
sterilisiertem Öl überschichtet, zweimal im Dampftopf eine Stunde lang aufgekocht und dann ebenfalls mit dem Anaërobier geimpft. Nach 18-tägigem Stehen im Thermostaten war das Eiweiß fast völlig zersetzt, die Reaktion schwach alkalisch, der Geruch sehr unangenehm, hauptsächlich nach Schwefelwasserstoff. Das mikroskopische Präparat zeigte auch hier, wie beim gefaulten Blutfibrin, ein einheitliches Bild mit vielen Sporen und sehr wenigen Vegetationsformen, ein Zeichen, daß die Fäulnis ihr Ende erreicht hatte. Die Untersuchung geschah in gleicher Weise wie beim Blutfibrin. $100 \mathrm{ccm}$ der durchkolierten Flüssigkeit wurden mit Weizenkleie gemischt und an ein Kaninchen verfüttert, auch hier ohne schädlichen Einfluß.

Die erste Ätherlösung des Destillates hinterließ wenige Tropfen Öl, die aber keine Reaktion auf Indol oder Skatol gaben; desgleichen war kein Kresol oder Phenol nachweisbar. Bei der Untersuchung des ursprünglichen Destillates machte sich durch Ansäuern des in Natronlauge aufgefangenen Wasserdampfdestillates mit Schwefelsäure der Geruch nach Essigsäure bemerkbar. Die Trennung der flüchtigen Fettsäuren wurde wieder mittels ihrer Calciumsalze ausgeführt.

$\begin{array}{lll}\begin{array}{c}\text { Gefunden } \\ 12,19-12,44^{\circ} \mathrm{Ca}\end{array} & \begin{array}{c}\text { Berechnet für } \\ \text { Kaprylsaures Calcium }\end{array} & 12,290^{\circ} \mathrm{Ca} \\ (5 \text { Bestimmungen }) & \text { Kapronsaures Calcium } & 14,84, \mathrm{Ca} \\ 14,29 \text { und } 15,00^{\circ}, \mathrm{Ca} & \end{array}$

Die bei der vorher versuchten fralstionierten Destillation zuletzt übergegangenen Tropfen waren über Nacht erstarrt und zeigten den Schmelzpunkt 43 bis $44^{\circ}$, der mit dem für Laurinsäure von $43,6^{0}$ übereinstimmen würde. Der im Fraktionierkölbchen verbliebene geringe Rückstand wurde zur Bestimmung der Phenylessig - bezw. Phenylpropionsäure mit Zinkoxyd und Wasser mehrere Male eingedampft, dann mit viel Wasser abgekocht und filtriert. Aus dem Filtrate schieden sich geringe Mengen nadelförmiger Krystalle aus, von denen ein Teil zu einer Zinkbestimmung benutzt wurde. Diese ergab 16,07\% Zink, während Phenylpropionsaures Zink 18,0\% und Phenylessigsaures Zink 19,5\% Zink verlangt.

Der andere Teil des auskrystallisierten Salzes wurde mit Salzsäure zersetzt und mit Äther ausgeschüttelt. Der $\bar{\Lambda}$ therrückstand erstarrte in der Kälte und zeigte den Schmelzpunkt $43^{\circ}$, während für Phenylpropionsäure $48,7^{\circ}$ und für Phenylessigsäure $76,5^{\circ}$ angegeben sind. Der beim Auskochen mit Wasser verbliebene Rückstand wurde ebenfalls mit Salzsäure zersetzt und mit Äther geschüttelt. Beim Abdunsten des Athers hinterblieb wenig gelbbraunes Öl, das in der Kälte erstarrte und den Schmelzpunkt $47-48^{\circ}$ zeigte. Das Öl wurde mit Wasser und reinstem Calciumkarbonat mehrere Male zur Trockne verdampft, mit Wasser ausgekocht und abfiltriert. Aus dem Filtrate schied sich beim starken Einengen wenig Salz aus, dessen Calciumgehalt zu 12,33\% gefunden wurde. Für Phenylpropionsaures Calcium berechnet sich $11,86^{\circ} \%$ und für Phenylessigsaures Calcium 12,93\% Ca. Es konnte wegen der zu geringen Menge nicht sicher festgestellt werden, ob ein Gemisch von Phenylpropionsäure mit Phenylessigsäure oder erstere allein vorlag. Aus dem von Harzbestandteilen abfiltrierten Rückstande der Dampistromdestillation schieden sich beim Einengen schön glänzende Blättchen aus, die, aus heißem Wasser umkrystallisiert, den Sehmelzpunkt $133^{0}$ zeigten, der mit dem für Skatolessigsäure bezw. Indolpropionsäure angegebenen von $134^{\circ}$ übereinstimmt. Mit Ferrichlorid gab eine Lösung der Krystalle ine starke Rotfärbung und mit Kaliumnitrat und Essigsäure ein schönes Krystallmagma aus mikroskopisch feinen zu Bündeln vereinigten Nadeln. Aus der Mutterlauge 
wurde noch eine zweite Krystallisation von gleichen Eigenschaften gewonnen. Das Filtrat davon wurde mit Äther geschüttelt und die wässerige Lösung auf Bernsteinsäure untersucht, jedoch ohne Erfolg. Aus dem mit heiBem Wasser aufgenommenen Ätherrückstand schied sich p-Oxyphenylpropionsäure, mit schleimigem Farbstoff verunreinigt, aus. Nach der Entfärbung der im Wasser gelösten Krystalle mit Tierkohle fielen Krystalle aus, die den Schmelzpunkt $123^{\circ}$ zeigten.

Die Mutterlauge gab beim Erwärmen mit Millons Reagens noch starke Rotfärbung und eine zweite Krystallisation vom Schmelzpunkt 120 . Bei diesem Versuche wurden also an Fäulniserzeugnissen aus Eieralbumin gefuniden: an Fettsäuren: Essigsäure, Kapron- und Kaprylsäure, Laurinsäure(?), ferner Phenyl. propionsäure, Skatolessigsäure bezw. Indolpropionsäure und p-Oxyphenylpropionsäure; zweifelhaft blieb die Anwesenheit von Phenylessigsäure; dagegen fehlten die einfacheren Fäulniserzeugnisse.

Ein Versuch, die Muttersubstanz der Indolpropionsäure, das Tryptophan, nach dem von $\mathrm{Hopkins}$ und $\mathrm{Cole}^{1}$ ) angegebenen Verfabren darzustellen, hatte keinen Frfolg. Zu dieser Untersuchung wurden $300 \mathrm{~g}$ Blutfibrin auf die angegebene Weise sterilisiert, mit dem Anaërobier geimpft und der Fäılnis überlassen. Sobald nach kurzer Zeit starke Gasentwickelung als Zeichen der begonnenen Fäulnis auftrat, wurde Chloroform zugesetzt, um das Bakterienwachstum zu vernichten, eine zu weit gehendo Spaltung zu verhindern und nur die tryptischen Enzyme weiter wirken zu lassen. Nach etwa 3 Wochen zeigte auch diese Probe schwach alkalische Reaktion. Das mikroskopische Präparat war ebenfalls frei von anderen Bakterienformen.

Die ganze Masse wurde nun erst durch Koliertücher, dann durch Faltenfilter filtriert, das Filtrat mit etwa $5 \%$ Schwefelsäure versetzt und mit etwa $150 \mathrm{ccm}$ einer $10 \%$-igen Lösung von Quecksilbersulfat in verdünnter Schwefelsäure gefällt. Der entstandene Niederschlag wurde abgesaugt, mit 5\%-iger Schwefelsäure gewaschen, dann in Wasser verteilt, mit Schwefelwasserstoff in der Wärme zerlegt und abfiltriert. Das durch Erhitzen von Schwefelwasserstoff befreite Filtrat wurde wieder mit Schwefelsäure bis zu 5\% versetzt und mit Quecksilbersulfatlösung gefällt, dann abgesaugt, der Rückstand mit Schwefelwasserstoff zerlegt, das Filtrat sorgfältig mit heißer Barytlauge gefällt und der Überschuß des Barythydrats durch Einleiten von Kohlensäure ausgefällt. Das Filtrat wurde eingeengt und mit Alkohol versetzt. Es fiel eine geringe Menge schleimiger Substanz aus, die in heißem Wasser löslich, aber in 45\%-igem Alkohol unlöslich war. Auch gab sie keine Reaktion auf Tryptophan.

Weiterhin wurde nach dem Verfahren von Brieger ${ }^{2}$ ) versucht, in gefaultem: Blutfibrin P tomaine nachzuweisen.

Zu dem Zwecke wurden ebenfalls $300 \mathrm{~g}$ sterilisiertes Blutfibrin mit dem Anaërobier geimpft und nach etwa drei Wochen aufgearbeitet. Die alkalisch reagierende Masse wurde mit Salzsäure angesäuert und mehrere Tage unter Ersatz des verdampfenden Wassers auf dem Wasserbade digeriert, dann abfiltriert und das Filtrat mit Bleiacetat gefällt. Der Niederschlag wurde abfiltriert, in Wasser suspendiert und mit Schwefelwasserstoff zersetzt. Das gebildete Bleisulfid wurde abfiltriert, das Filtrat. eingedampft und mehrmals mit Alkohol ausgezogen. Ein Drittel des Alkoholauszuges. wurde eingedampft, in Wasser gelöst und zur Prüfung auf Cholin und Neuridin mit.

1) Journ. of. Physiology 1901, 27, 418; 1902, 29, 451; Biochem. Centralbl. 1903, 1, 658.

2) Brieger, Untersuchung über Ptomaine 1885, 2, 53; 3, 13. 
Pikrinsäure versetzt; jedoch trat nur eine so geringe Abscheidung ein, daß eine nähere Bestimmung unmöglich war. Die übrigen zwei Drittel des alkoholischen Auszuges wurden mit alkoholischer Quecksilberchloridlösung gefällt, mehrere Tage absitzen gelassen, mit Alkohol ausgewaschen, der Niederschlag mit viel Wasser ausgekocht und abfiltriert. Im Filtrate wurde das Quecksilber mit Schwefelwasserstoff ausgefällt, abfiltriert, das Filtrat eingedampft, mit Alkohol aufgenommen und mit alkoholiseher Platinchloridlösung versetzt.

Beim Verdunsten blieben ebenfalls nur wenige Krystalle zurück, die zu einer genaueren Untersuchung nicht ausreichten. Das Filtrat der durch die alkoholische Quecksilberchloridlösung entstandenen Fällung wurde durch Schwefelwasserstoff vom überschüssigen Quecksilberchlorid befreit, das Filtrat hiervon mit Natriumkarbonat neutralisiert und eingedampft, mit Alkohol ausgezogen und dieser Auszug wieder mit alkoholischer Quecksilberchloridlösung versetzt. Nach mehreren Tagen wurde der entstandene Niederschlag abfiltriert, mit Wasser ausgekocht, die wässerige Lösung durch Schwefelwasserstoff rom Quecksilber befreit, das Filtrat mit wässeriger Platinchloridlösung versetzt und langsam verdunsten gelassen. Zurück blieben nur wenige Krystalle von Platinchlorid.

Es konnten also keine Ptomaine mit Sicherheit nachgewiesen werden.

Die Ergebnisse dieser Untersuchungen stimmen einerseits mit den von $\mathrm{Nencki}$ und Bienstock erhaltenen gut überein, wonach nämlich die obligaten Anaërobier die Proteinstoffe nur bis zu gewissen hochmolekularen Verbindungen abbauen, andererseits ergänzen sie die chemischen Untersuchungen von $\mathrm{W}$ a $11 \mathrm{a} \mathrm{ch}$ über Bacillus putrificus.

\section{Fütterningsversuche.}

Man hat bekanntlich häufig Erkrankungen von ganzen Viehbeständen auf das Verfüttern von Baumwollsaatmehl, besonders amerikanischer Herkunft, zurückgeführt.

Olig hat bereits gelegentlich seiner Untersuchungen Fütterungsversuche mit zersetztem Baumwollsaatmehl angestellt, um festzustellen, ob bei der Fäulnis giftige Stoffe entstehen. Er fütterte Meerschweinchen und Kaninchen kurze Zeit hindurch mit verhältnismäßig geringen Mengen gefaulten Baumwollsaatmehles, beobachtete dabei aber keinerlei Giftwirkung.

Da es möglich ist, daß in dem Verdauungskanal der größeren Haustiere die Vorgänge etwas anders verlaufen, und daß die Giftwirkung erst bei längerer Fütterung durch Akkumulation zustande kommt, haben wir einige Versuche mit Schafen und Zi egen ausgeführt, die wochenlang mit verschieden stark gefaulten Mehlen gefüttert wurden.

\section{Versueh I.}

$4 \mathrm{~kg}$ Baumwollsaatmehl wurden in Mengen von je $500 \mathrm{~g}$ mit $50 \%$ Wasser angerührt und bei Luftzutritt der Fäulnis überlassen. Die einzelnen Proben wurden in verschiedenen Stufen der Fäulnis innerhalb zweier Tage in vier Gaben an eine Zi iege verfüttert.

Zur Fütterung wurde das gefaulte Mehl mit lauwarmem Wasser zu einem dünnen Brei angerührt. Dieser wurde durch einen in den Schlund der Ziege eingeführten Gummischlauch mit aufgesetztem Glastrichter ihr eingegossen.

Vor dem Versuche erhielt die Ziege erst vier Tage lang je $1 / \mathrm{s} \mathrm{kg}$, dann zwei 
Tage lang je $1 / 4 \mathrm{~kg}$ und ebenso zwischen den zwei Versuchstagen mit faulem Mehle täglich je $1 / 4 \mathrm{~kg}$ gutes Baumwollsaatmehl.

Der bakterielle und chemische Befund der einzelnen Proben war folgender:

Erste Probe, nach 21-tägiger Fäulnis: Starke Schimmelschicht; Geruch fanlig; Reaktion aufen alkalisch, innen sauer; anaërobe Hochkultur zeigt kein Wachstum.

$\mathrm{Z}$ weite Probe, nach 28-tägiger Fäulnis: Wie vorher nur stärker alkalische Reaktion.

Dritte Probe, nach 35-tägiger Fäulnis: Wie vorher, nur ist die saure Reaktion fast verschwunden.

Vierte Probe, nach 57-tägiger Fäulnis: Reaktion im Innern nur noch ganz schwach sauer; anaërobe Hochkultur zeigt sehwaches Wachstum.

Fünfte Probe, nach 64-tägiger Fäulnis: Wie vorher, nur ist das Wachstum der anaëroben Hochknltur stärker.

Sechste Probe, nach 79-tägiger Fäulnis: Reaktion alkalisch; anaërobe Hochkultar zeigt starkes Wachstum.

Siebente Probe, nach 85-tägiger Fänlnis: Es tritt schon freies Ammoniak auf; der Geruch ist äußerst widerlich; die Hochkuitur zeigt sehr starkes Wachstum.

Achte Probe, nach 93-tägiger Fânlnis: Wie vorher.

Irgend eine Gesundheitsschädigung der Ziege wurde während des ganzen Versuches nicht beobachtet.

\section{Versuch II.}

Bei diesem Versuche wurde ein Hammel längere Zeit mit einen durch Fäulnis an der Luft alkalisch gewordenen Baumwollsaatmehl gefüttert. Um eine möglichst schnelle Abstumpfung der bei der freiwilligen Fäulnis anfangs entstehenden Säuren berbeizuführen, wurde das Mehl öfters gründlich durchgearbeitet, sodaß die oberen alkalischen Teile nach unten gelangten. Nach ungefähr sechs Wochen war die Reaktion in der ganzen Masse schwach alkalisch und eine anaërob angelegte Hochkultur zeigte auch schon schwache Entwickelung. Während der ganzen Dauer des Versuches wurde durch Anlegen solcher Kulturen die sich allmählich steigernde Entwickelung von Anaërobiern verfolgt. Die Verfütterung des Mehles erfolgte in gleicher Weise wie bei der Ziege mittels eines Schlauches. Da das widerlich riechende Mehl von dem Tiere nur ungern genommen wurde, wurde, um dieses nicht zu sehr anzustrengen, in kleineren Zwischenräumen die Fütterung auf einen Tag unterbrochen.

Der Hammel erhielt an vier aufeinanderfolgenden. Tagen je $100 \mathrm{~g}$ des 45 Tage gefaulten Mehles, dann nach einem Tage Unterbrechung vier Tage lang $130 \mathrm{~g}$ des 50 Tage gefaulten Mehles und wiederum nach einem Tage Unterbrechung zwei Tage lang $200 \mathrm{~g}$ des etwa 65 Tage gefaulten Mehles.

Außer der zeitweilig verminderten Freßlust traten Krankheitserscheinungen bei dem Tiere nicht auf.

\section{Versuch III.}

Ein andere Hammel wurde mit Kokosnulamehl gefütert, das ebenfalls bis zur völligen alkalischen Reaktion der natürlichen Fäulnis überlassen worden war. Die Versuchsanordnung entsprach ganz der des Versuches II. Auch in diesem Falle wurden nachteilige Folgen nicht beobachtet.

Versuch IV.

Zu diesem Versuche wurde sterilisiertes Baumwollsaatmehl verwendet, das mit drei Stämmen des in freiwillig gefaulten Futtermitteln stets gefundenen Bacillus putrificus geimpft und von ihm längere Zeit zersetzt worden war. 
Als Versuchstier diente ein Hammel. Fr wurde 33 Tage lang mit geimpftem Mehl im Alter von vier bis zu siebenundsechzig Tagen gefüttert.

Die Reaktion des geimpften Mehles war vom Beginn der Fütterung an schwach sauer und diese Reaktion trat später stärker auf.

Fine schädliche Wirkung trat aber auch hier trotz der langen Dauer des Versuchs nicht ein.

Sämtliche Versuche ergaben also, daß auch bei längerer Verfütterung gefaulten Baumwollsatmehles oder Kokosnufbehles im allgemeinen Gesundheitsschädigungen bei Ziegen und Hammeln nicht einzutreten schoinen.

\title{
1905̆-er Himbeersäfte und -syrupe böhmischer Herkunft.
}

Von

\author{
Adjunkt R. Krźiźan und Assistent W. Plahl.
}

Mitteilung aus der k. k. Untersuchungsanstalt für Lebensmittel in Prag (Deutsche Universität). Vorstand: Prof. Dr. F. Hueppe.

Obwohl in der letzten Zeit eine Reihe von Untersuchungen über die Zusammensetzung von Himbeersäften und -syrupen veröffentlicht worden sind, erschien uns doch eine Vermehrung des verhältnismäßig noch spärlich vorhandenen Analysenmaterials als nicht ganz überflüssig, zumal über österrejchische Himbeersäfte überhaupt noch fast keine Zahlen vorliegen. Ein endgültiges Urteil über diesen Gegenstand wird ohnehin erst nach jahrelangen, sorgfältig ausgeführten Untersuchungen möglich sein.

A. Beythie $n^{1}$ ) führt hinsichtlich der s. Z. von F. Evers ${ }^{2}$ ) gefundenen abnorm niedrigen Zahlen an, daß diese Bestimmungen höchstwahrscheinlich mit schwefelhaltigem Leuchtgas ausgeführt worden sind. Diese Erklärung hat etwas für sich und läft sich nicht ohne weiteres von der Hand weisen.

Das uns in Prag zur Verfügung stehende Leuchtgas ist nun außerordentlich reich an organischen Schwefelverbindungen. Mit diesem Faktor mußte daher gerechnet werden. Der absolute Schwefelgehalt des Prager Leuchtgases ist uns zwar nicht bekannt, er mub jedoch beträchtlich sein, denn sämtliche hei uns im Labaratorium gebrauchten kupfernen Wasserbäder und Trockenschränke zeigen an der Unterseite starke Ausblühongen des im heißen Zustande weif, nach dem Erkalten aber blaugrün aussehenden wasserfreien Kupfersulfats. Verdampft man Wasser in einer Platinschale üher der freien Bunsen-Flamme, so erhält man in der kürzesten Zeit an der Unterseite der Schale stark sauer reagierende Tröpfchen, die nichts anderes sind als verdünnte Schwefelsäure.

Um einen Anhaltspunkt für den Schwefelgehalt unseres Leuchtgases bei der Verwendung im Laboratorium zu gewinnen, fubrten wir mehrere Versuche aus, von denen wir blof folgende herausgreifen:

I. $1 \mathrm{~g}$ Natriumbikarbonat, das völlig frei von Sulfat war, wurde in einer Weinschale mit ein wenig Wasser angerührt und die Masse behufs Erzielung einer großen Oberflächo durch Schwenken über den Schalenboden ausgebreitet, um ähnliche Verhältnisse zu schaffen, wie sie bei Aschenanalysen vorliegen. Nach dem Eintrocknen auf dem Wasserbade, warde die

1) Diese Zeitschrift 1904, 8, 545.

2) Zeitschr. offentl. Chem. 1904, 10, 319. 